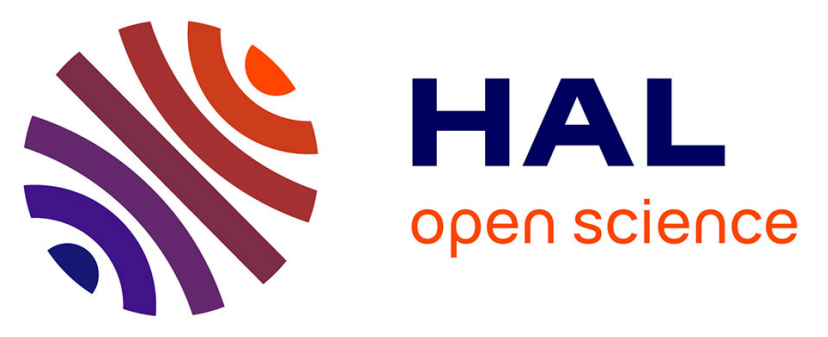

\title{
Photoinduced linkage isomers in a model ruthenium nitrosyl complex: Identification and assignment of vibrational modes
}

Artem A Mikhailov, Theo Woike, Axel Gansmüller, Dominik Schaniel, Gennadiy A Kostin

\section{To cite this version:}

Artem A Mikhailov, Theo Woike, Axel Gansmüller, Dominik Schaniel, Gennadiy A Kostin. Photoinduced linkage isomers in a model ruthenium nitrosyl complex: Identification and assignment of vibrational modes. Spectrochimica Acta Part A: Molecular and Biomolecular Spectroscopy [1994-..], 2021, 263, pp.120217. 10.1016/j.saa.2021.120217 . hal-03405097

\section{HAL Id: hal-03405097 \\ https://hal.univ-lorraine.fr/hal-03405097}

Submitted on 27 Oct 2021

HAL is a multi-disciplinary open access archive for the deposit and dissemination of scientific research documents, whether they are published or not. The documents may come from teaching and research institutions in France or abroad, or from public or private research centers.
L'archive ouverte pluridisciplinaire HAL, est destinée au dépôt et à la diffusion de documents scientifiques de niveau recherche, publiés ou non, émanant des établissements d'enseignement et de recherche français ou étrangers, des laboratoires publics ou privés.

\section{(1) (1) $\$$}

Distributed under a Creative Commons Attribution - NonCommercial - NoDerivatives| 4.0 


\title{
Photoinduced linkage isomers in a model ruthenium nitrosyl complex: identification and assignment of vibrational modes
}

\author{
Artem A. Mikhailov ${ }^{a}$, Theo Woike ${ }^{b}$, Axel Gansmüller ${ }^{b}$ Dominik Schaniel $^{b}$ and Gennadiy A. Kostin ${ }^{a}$ \\ a Nikolaev Institute of Inorganic Chemistry, Siberian Branch of the Russian Academy of Sciences, 3 Acad.
} Lavrentiev Avenue, Novosibirsk 630090, Russian Federation

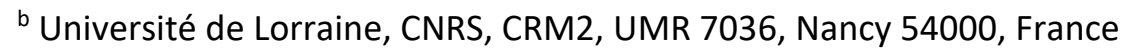

\begin{abstract}
Photoinduced NO-linkage isomers were investigated in the solid state of labelled trans-[Ru( $\left.\left.{ }^{14 / 15} \mathrm{NO}\right)\left(\mathrm{py}_{4}\right) \mathrm{F}\right]\left(\mathrm{ClO}_{4}\right)_{2}$ complex by combined IR-spectroscopy and DFT calculations. The calculated IR-spectra show features similar to the experimental data allowing reliable assignment of the vibrational bands. The structural change from the Ru-NO (GS) to the Ru-ON (MS1) and Ru- $\eta^{2}$-(NO) (MS2) linkage configuration leads to the downshift of the $v(N O)$ and $v(R u-(N O)$ ) bands, and a corresponding increase of the energy of the $v(R u-F)$ band. The shift of the bands corresponds to the change of the Ru-(NO) and Ru-F bond lengths: increase of the Ru-(NO) bond length leads to the decrease of the energy of the $v(R u-(N O))$ band; decrease of the Ru-F bond length leads to the increase of the energy of the $v(R u-F)$ band. These observations can be extrapolated to the family of related nitrosyl complexes and therefore be used for the qualitative prediction of the Ru-(NO) and Ru- $\mathrm{L}_{\text {trans-to-No }}$ bond lengths of different linkage isomers in the framework of one complex. While the formation of linkage isomers is a reversible process, long-time irradiation sometimes induces irreversible reactions such as the release of NO. Here, we show that the photolysis of trans$\left[\mathrm{Ru}\left({ }^{14 / 15} \mathrm{NO}\right)\left(\mathrm{py}_{4}\right) \mathrm{F}\right]\left(\mathrm{ClO}_{4}\right)_{2}$ in $\mathrm{KBr}$ pellets may lead to the release of nitrous oxide $\mathrm{N}_{2} \mathrm{O}$, conceivably through the formation of a $\left\{\mathrm{Ru}-\left(\mathrm{K}^{2}-\mathrm{ONNO}\right)\right\}$ intermediate.
\end{abstract}

\section{Introduction}

Metal nitrosyl complexes (M-NO) are a wide class of materials exhibiting outstanding photochemical properties. The photoexcitation is based on the charge transfer from the metal center to the antibonding empty $\pi^{*}(\mathrm{NO})$ orbital of the coordinated nitrosyl ligand resulting either in the isomerization of the NO-ligand (formation of linkage isomers) or in the release of nitric oxide [1,2]. Photoinduced linkage isomers in solids can be used in data storage technologies based on holography [3], whereas the NO release from nitrosyl ruthenium complexes in solution renders these complexes attractive for photodynamic therapy applications (PDT), due to generation of highly reactive ruthenium species and free NO $[2,4-6]$.

In general, the investigation and search for novel nitric oxide donors is an important field due to known biological properties of NO [7-10]. Recently, many researchers emphasized also the significance of investigating new nitric oxide carriers with respect to the fight with COVID-19 [11-14]. The mechanism of nitric oxide photo-release in solution is subject of debate and might involve several intermediates. One possible reaction scheme involves metastable linkage isomers as intermediates and was schematically described as follows [15]:

$$
\mathrm{L}_{5} \mathrm{Ru}^{2+}-\mathrm{NO}^{+} \rightarrow \mathrm{L}_{5} \mathrm{Ru}^{2+}-\eta^{2}-\left(\mathrm{NO}^{+}\right)+\text {Solvent } \rightarrow \mathrm{L}_{5} \mathrm{Ru}^{3+} \text { (Solvent) }+\mathrm{NO}^{0},
$$

where $\eta^{2}-\left(\mathrm{NO}^{+}\right)$corresponds to one of the nitrosyl linkage isomers (MS2 in current case). In this case, since for the NO release two photons are needed to be absorbed by the ruthenium complex, a longer lifetime of the linkage isomers that constitute the intermediate state may thus provide a better efficiency of nitric oxide release.

In fact, nitrosyl linkage isomers can be generated in various media, from solutions over gels to crystalline solids, however the solid state offers advantages for both the stabilization of the isomers and their structural 
characterization [6,15-19]. As a matter of fact, these photoinduced nitrosyl linkage isomers corresponding to different types of nitrosyl ligand coordination to the metal, represented by M-NO (GS), M-ON (MS1) or M- $\eta^{2}$-(NO) (MS2, side bond) coordination (Fig. 1) are so-called metastable states. The metastability is characterized by an energy barrier separating the photoinduced linkage isomers MS1 and MS2 from the ground state GS. The higher the barrier the more stable the linkage isomer, which is very often indicated in the form of a so-called decay temperature $T_{d}$, defined as the temperature where the decay rate constant of the metastable linkage isomer is $0.001 \mathrm{~s}^{-1}[20]$. This type of isomerism is characteristic for different metals, but the most prominent results and effects was observed in octahedrally coordinated ruthenium complexes with the general formula of $\mathrm{L}_{5} \mathrm{Ru}-\mathrm{NO}$, due to the much higher decay temperatures of metastable states compared to other central metal atoms [20-25].
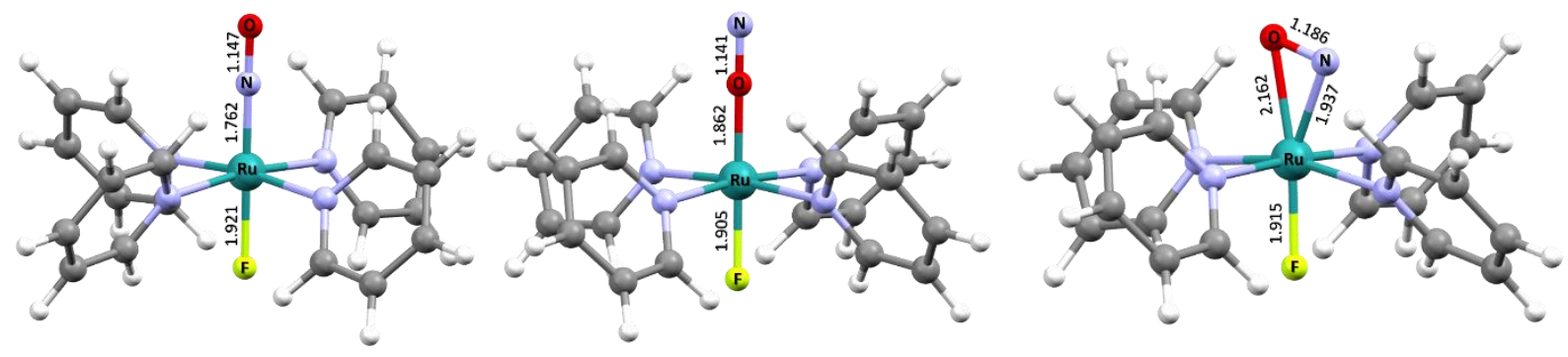

Fig. 1. The calculated (DFT, ADF, B3LYP/TZP) geometries of GS (left), MS1 (middle) and MS2 (right) for trans- $\left[\mathrm{Ru}(\mathrm{NO})\left(\mathrm{py}_{4}\right) \mathrm{F}\right]^{2+}$ with chosen depicted bond lengths $[\AA]$.

Among other methods applied for the study of the different linkage modes, IR-spectroscopy is the most powerful and sensitive tool to detect the changes of the NO coordination, since especially the $\mathrm{v}(\mathrm{NO})$ stretching vibration has a large amplitude due to a very strong derivative of the dipole moment [26-30]. The relative energetic position of the bands gives a clear view into the change of the force constants which are a measure of the bond forces between $\mathrm{M}-\mathrm{NO}$ and $\mathrm{N}-\mathrm{O}$ even with small fractions of linkage isomers, which cannot be observed by e.g. X-ray diffraction [31]. The common energy range of the $v(N O)$ stretching vibration in GS is about $1900-1800 \mathrm{~cm}^{-1}$, which shifts to lower energy by about 150 and $300 \mathrm{~cm}^{-1}$ in case of MS1 and MS2 respectively. This behavior is well known and supported by other spectroscopic and diffraction data as well as DFT calculations [22,23,26,31]. Other signatures of the nitrosyl linkage are the changes of the $v(\mathrm{Ru}-\mathrm{NO})$ stretching vibrations, the $\delta(\mathrm{Ru}-\mathrm{N}-\mathrm{O})$ deformation modes and the $v\left(\mathrm{Ru}-\mathrm{L}_{\text {trans }}\right.$ to-No) bands, which are lying below $700 \mathrm{~cm}^{-1}$. However, contrary to the well-established data of the high energy range, the assignment of the bands in the low energy range (below $700 \mathrm{~cm}^{-1}$ ) is not so obvious even in the ground state. A clear assignment is important for the explanation of the formation of linkage isomers e.g. on the basis of the Jahn-Teller effect [32-34]. Here, the $\delta(\mathrm{M}-\mathrm{N}-\mathrm{O})$ deformation mode is the natural movement for the rotation of the NO ligand and in consequence, using $4 \mathrm{~m}$ symmetry, the two-fold degeneration of this mode is lifted.

Earlier works $[35,36]$ postulate, that the $v(\mathrm{Ru}-\mathrm{NO})$ vibration possess a higher energy compared to the $\delta(\mathrm{Ru}-\mathrm{N}-\mathrm{O})$ mode, which is shown by IR and Raman spectroscopy using labeled ${ }^{15} \mathrm{NO}$ nitrosyl ligands in the $\left[\mathrm{Ru}(\mathrm{NO}) \mathrm{X}_{5}\right]^{2-}$ complexes $\left(\mathrm{X}=\mathrm{Cl}^{-}, \mathrm{Br}^{-}, \mathrm{l}^{-}\right)$. This is confirmed by normal-coordinate analysis of trans- $\left[\mathrm{Ru}(\mathrm{NO})(\mathrm{py})_{4} \mathrm{Cl}\right]^{2+}(\mathrm{Py}=$ pyridine $)$ and trans- $\left[\mathrm{Ru}(\mathrm{NO}) \mathrm{Cl}_{4} \mathrm{~F}\right]^{2-}[37,38]$, as well as by the data obtained on phthalocyanine $\left(\mathrm{pc}^{2-}\right)$ ruthenium complexes with different trans-to-NO ligands [39]. For instance, in trans-[Ru(NO)(pc)F] the v(Ru-NO), $\delta(\mathrm{Ru}-\mathrm{N}-\mathrm{O})$ and $v(\mathrm{Ru}-\mathrm{F})$ modes were assigned to the bands at 624,581 and $483 \mathrm{~cm}^{-1}$ respectively. On contrary, using DFT calculations and labelled $\left({ }^{15} \mathrm{NO}\right)$ samples it was indicated that the $\delta(\mathrm{Ru}-\mathrm{N}-\mathrm{O})$ mode has a higher energy than $v(\mathrm{Ru}-\mathrm{NO})$ in different complexes of cis-[Ru(NO)(TPA)X] $]^{2 / 3+}$, where TPA is tris(2-pyridylmethyl)amine [40]. The same sequence of these bands was shown for amine complex $\left[\mathrm{Ru}(\mathrm{NO})\left(\mathrm{NH}_{3}\right)_{5}\right] \mathrm{Br}_{3}$ [41]. Hence, the mutual position of these bands is influenced by the different ligand environment of the ruthenium center.

In the study of linkage isomers in $\mathrm{K}_{2}\left[\mathrm{Ru}(\mathrm{NO})\left(\mathrm{NO}_{2}\right)_{4} \mathrm{OH}\right][42]$ the $v(\mathrm{Ru}-\mathrm{NO})$ and $\delta(\mathrm{Ru}-\mathrm{N}-\mathrm{O})$ modes were assigned to the bands at 633 and $625 \mathrm{~cm}^{-1}$ for GS and at 612 and $603 \mathrm{~cm}^{-1}$ for MS1 respectively. The reverse sequence of the energy of the bands was reported for $\mathrm{Na}_{2}\left[\mathrm{Ru}(\mathrm{NO})(\mathrm{CN})_{5}\right] \cdot 2 \mathrm{H}_{2} \mathrm{O}$ [43]. The bands of $\delta(\mathrm{Ru}-\mathrm{N}-\mathrm{O})$ in GS, MS1 and MS2 were found at $643,592,595 \mathrm{~cm}^{-1}$, whereas the bands of $\mathrm{v}(\mathrm{Ru}-\mathrm{NO})$ were observed at 583, 539 and $523 \mathrm{~cm}^{-1}$, 
respectively. However, for both studies, the data were not supported by experiments with ${ }^{15} \mathrm{~N}$ labelled species, and the bands were assigned tentatively. In [44] the v(Ru-NO) and $\delta(\mathrm{Ru}-\mathrm{N}-\mathrm{O})$ modes in GS of trans-[Ru(NO)(en) $\left.{ }_{2} \mathrm{Cl}\right] \mathrm{Cl}_{2}$ and trans-[Ru(NO)(en) ${ }_{2} \mathrm{Br}_{\mathrm{Br}} \mathrm{Br}_{2}$ complexes were assigned to the bands at 617 and $609 \mathrm{~cm}^{-1}$, and 608 and $600 \mathrm{~cm}^{-1}$, respectively. The corresponding bands of MS1 were found at 479 and $436 \mathrm{~cm}^{-1}$, and 473 and $432 \mathrm{~cm}^{-1}$. However, the authors emphasize ${ }^{15} \mathrm{~N}$-substitution experiments are needed to make clear whether the $617 \mathrm{~cm}^{-1}$ or the 609 $\mathrm{cm}^{-1}$ band corresponds to $\mathrm{v}(\mathrm{Ru}-\mathrm{NO})$ or $\delta(\mathrm{Ru}-\mathrm{N}-\mathrm{O})$ )". In complexes of $\left[\mathrm{Ru}(\mathrm{NO})\left(\mathrm{NH}_{3}\right)_{5}\right]^{3+}$ with different anions [45] the band of $\delta(\mathrm{Ru}-\mathrm{N}-\mathrm{O})$ was found to have higher energy than $v(\mathrm{Ru}-\mathrm{NO})$, but again the bands of linkage isomers were not precisely assigned to the $\delta(\mathrm{Ru}-\mathrm{N}-\mathrm{O})$ or $\mathrm{v}(\mathrm{Ru}-\mathrm{NO})$ modes. The study of diverse pyridine complexes trans$\left[\mathrm{Ru}(\mathrm{NO})\left(\mathrm{py}_{4}\right) \mathrm{X}\right]^{2+}\left(\mathrm{X}=\mathrm{Cl}^{-}, \mathrm{Br}^{-}\right)$reveal that the energy of $\delta(\mathrm{Ru}-\mathrm{N}-\mathrm{O})$ bands $\left(614,609 \mathrm{~cm}^{-1}\right)$ is higher compared to $v(\mathrm{Ru}-$ NO) $\left(606,603 \mathrm{~cm}^{-1}\right)$ in GS, whereas bands of linkage isomers at 483 and $567 \mathrm{~cm}^{-1}$ were tentatively attributed to the $\delta(\mathrm{Ru}-\mathrm{N}-\mathrm{O})$ or $\mathrm{v}(\mathrm{Ru}-\mathrm{X})$ vibrations [46]. Surprisingly, though linkage isomerism in nitrosyl compounds is a known phenomenon, the detailed investigation of spectroscopic properties of the linkage isomers and particularly the assignment of the low-energy bands of metastable states was never explored systematically. Moreover, the precise knowledge of the energetic positions of the $\delta(\mathrm{Ru}-\mathrm{N}-\mathrm{O}), v(\mathrm{Ru}-\mathrm{NO})$ and $v(\mathrm{Ru}-\mathrm{L}$ trans-to-No) vibrational bands in the range below $700 \mathrm{~cm}^{-1}$ provides basic information about the change of the bond energies upon nitrosyl ligand isomerization.

In order to shine light on these questions and perform unambiguous assignment of the low-energy bands of the photoinduced linkage isomers, we present the detail description of the vibrational bands of IR-spectra of all linkage isomers in trans-[Ru(NO) $\left.\left(\mathrm{py}_{4}\right) \mathrm{F}\right](\mathrm{ClO} 4)_{2}$ by combined IR-spectroscopy and DFT calculations including investigation of the ${ }^{15} \mathrm{NO}$ labelled complex. This complex is particularly suited for the purpose, since earlier we studied the mechanism of photoisomerization of nitrosyl ligands, the thermal stability of MS1 and MS2, by calorimetric, spectroscopic and structural analysis of the linkage isomers in this compound $[22,23]$. The linkage isomers can be generated with high efficiency, using blue light irradiation for MS1 and subsequent near-infrared exposure for MS2. Furthermore, as already reported in earlier studies, long-time irradiation might lead to NO release even in the solid state [47-49], however, a clear identification of the NO release and/or the photoproducts is difficult. In the framework of our current study with ${ }^{15} \mathrm{NO}$ labelled compounds, we detect the product of the nitric oxide photorelease in the solid state (the crystalline complex embedded in $\mathrm{KBr}$ pellets) and we propose a possible reaction path towards the formation of nitrous oxide $\mathrm{N}_{2} \mathrm{O}$.

\section{Experimental}

\section{Synthesis}

Trans-[Ru( $\left.\left.{ }^{14} \mathrm{NO}\right)(\mathrm{py})_{4} \mathrm{~F}\right]\left(\mathrm{ClO}_{4}\right)_{2}$ was prepared according to the reported methods $[22,50,51]$. The labelled complex trans- $\left[\mathrm{Ru}\left({ }^{15} \mathrm{NO}\right)\left(\mathrm{py}_{4}\right) \mathrm{F}\right]\left(\mathrm{ClO}_{4}\right)_{2}$ was synthesized from labelled $\mathrm{K}_{2}\left[\mathrm{Ru}^{15} \mathrm{NOCl}_{5}\right]$ obtained using $\mathrm{Na}^{15} \mathrm{NO}_{2}$. The substitution of ${ }^{15} \mathrm{~N}$ against ${ }^{14} \mathrm{~N}$ in the nitrosyl ligand is nearly $100 \%$, as confirmed in the absence of any $\mathrm{v}\left({ }^{14} \mathrm{~N}-\mathrm{O}\right)$ band area.

\section{Infrared spectroscopy}

IR spectroscopy measurements were performed using a Nicolet 5700 FT-IR spectrometer with a resolution of 2 $\mathrm{cm}^{-1}$ in the range $400-4000 \mathrm{~cm}^{-1}$. The sample was grinded, mixed with $\mathrm{KBr}$, and pressed into pellets. $\mathrm{KBr}$ pellets were bonded by silver paste on the coldfinger of a closed cycle cryostat (Oxford Optistat V01) and irradiated by LED through $\mathrm{KBr}$ windows with light. For measurements in the range $670-60 \mathrm{~cm}^{-1}$ (resolution of $1 \mathrm{~cm}^{-1}$ ) the sample was mixed with polyethylene (PE) and pressed into pellets. Equally, the windows of the cryostat for this spectral region are PE windows. In order to perform irradiation, a new head for the optical cryostat was constructed, with an additional window (common glass) adjacent to the PE windows. MS1 was generated by the irradiation with light of 420-450 nm, $100 \mathrm{~mW}$. MS2 was generated by the subsequent irradiation of MS1 with light of 850-940 nm, $100 \mathrm{~mW}$. Experiments were carried out at $10 \mathrm{~K}$. The cryostat allows controlling the temperature in the range of 9-320 K. The 
populations of metastable states were calculated from the decrease of the area under v(NO) band in GS (\% $\% 100$

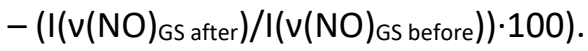

\section{Density functional theory calculations}

Starting geometries were optimized from available experimental structural data obtained for all linkage isomers [23]. DFT calculations of trans-[Ru(NO)(py) $\left.{ }_{4} \mathrm{~F}\right]^{2+}$ ion in the gas phase were performed using the ADF2017 package [52]. For geometry optimization, the hybrid B3LYP functional [53] and the triple-z-quality with one polarization function (TZP) basis set [54] were used. No symmetry restrictions were imposed on the geometry for the optimization. A closed-shell electron configuration and the scalar relativistic zero-order regular approximation (ZORA) [54] for the Hamiltonian were applied. The widely applied B3LYP functional was selected due to the good agreement between calculated structures of ruthenium complexes and experimental data in previous investigations [6]. IR-spectra were calculated for optimized structures using the same level of theory. Scaling factors (shift of the calculated bands) for calculated IR-spectra of GS, MS1 and MS2 were $-13,-16$ and $-15 \mathrm{~cm}^{-1}$, respectively. The scaling (subtraction of $-13,-16$ and $-15 \mathrm{~cm}^{-1}$ from the calculated spectra of GS, MS1 and MS2 respectively) allowed to have a better match with the experimental bands in the range of $700-400 \mathrm{~cm}^{-1}$. Tables with calculated atomic coordinates, frequencies and Hessian matrixes of ADF are placed in Supporting information (Tables S4-S15). The assignment of the vibrational modes is made based on the position, intensity and sequence of the calculated bands with respect to the experimental data. Independent assessment of the reliability of the ADF calculations was made by performing an additional calculation using the CASTEP19.11 code [55]. In this case, the structure optimization (no symmetry restrictions) and calculation of IR spectra for GS, MS1 and MS2 of trans$\left[\mathrm{Ru}\left({ }^{14} \mathrm{NO}\right)(\mathrm{py})_{4} \mathrm{~F}\right]^{2+}$ were performed using PBE functional [56] with ZORA relativistic treatment [54] and Norm conserving pseudopotentials (NCP19) [57] Plane wave basis set cut-off was set to $900 \mathrm{eV}$ using a standard grid of 2.0 and a fine grid of 3.0. The isolated cations were placed in a $30 \times 30 \times 30 \AA^{3}$ cell using one k-point at the Gamma point. The geometry optimization was performed with strict convergence tolerance criteria to avoid significant imaginary vibrations for the IR calculations (1E-7 eV/atom total energy convergence; $1 \mathrm{E}-3 \mathrm{eV} / \AA \AA$ max ionic force; $5 \mathrm{E}-4 \AA \AA$ max ionic displacement). No scaling factors were applied for the calculated IR frequencies. The obtained calculated bond lengths and frequencies are summarized in Table S2 and S3.

\section{Results and discussion}

\section{IR-spectra of trans-[Ru( $\left.\left({ }^{14} \mathrm{NO}\right)\left(\mathrm{py}_{4}\right) \mathrm{F}\right](\mathrm{ClO} 4)_{2}$}

The discrimination between GS, MS1 and MS2 is performed by at first stepwise irradiation with blue or violet light, resulting in a gradual decrease of GS bands and a corresponding increase of MS1 bands, followed by radiation with IR light, whereby the new bands of MS1 decrease completely, but bands of MS2 arise and bands of GS increase due to the partially back transfer.

The high-energy range of the IR-spectra of GS, MS1 and MS2 is shown in Fig. 2. The most intense bands with maxima at 1921 and $1914 \mathrm{~cm}^{-1}$ corresponds to the $v(N O)$ stretching vibrations (see Table 1). The band splitting of 7 $\mathrm{cm}^{-1}$ is due to two inequivalent ruthenium complexes with slightly different crystal environment $[22,23]$. The $v(\mathrm{NO})$ bands of MS1 are shifted by $151 \mathrm{~cm}^{-1}$ to lower energy. There are again two maxima (1770 and $1763 \mathrm{~cm}^{-1}$ ) with reachable population of $~ 80 \%$. Unlike GS and MS1, the corresponding band of MS2 shows at least four maxima (1600, 1580, 1591 and $1564 \mathrm{~cm}^{-1}$ ) indicating an additional splitting of the bands. Since the small increased absorption at $1571 \mathrm{~cm}^{-1}$ is overlapped with the low intense band of pyridine at $1573 \mathrm{~cm}^{-1}$ in GS we cannot unequivocally assign this band to MS2. The reachable population of MS2 is 30\%. The origin of this additional splitting is a completely different coordination type of the NO ligand in MS2 (side bond coordination with an angle $\mathrm{Ru}-\mathrm{N}-\mathrm{O}$ of $84^{\circ}$ vs. almost $180^{\circ}$ in case of GS and MS1). Close inspection of the behavior of the $\mathrm{v}(\mathrm{NO})$ band of GS during the irradiation reveals that the band with maximum at $1921 \mathrm{~cm}^{-1}$ is much faster transferred to MS1 with the 
corresponding maximum at $1770 \mathrm{~cm}^{-1}$ than the one at $1914 \mathrm{~cm}^{-1}$ with the corresponding maximum at $1763 \mathrm{~cm}^{-1}$ (see Fig. 2). Thus, the $v(N O)$ band at $1921 \mathrm{~cm}^{-1}$ of GS corresponds to the $v(N O)$ stretching mode of MS1 at $1770 \mathrm{~cm}^{-}$ ${ }^{1}$ while the band at $1914 \mathrm{~cm}^{-1}$ of GS corresponds to the one at $1763 \mathrm{~cm}^{-1}$ of MS1. The first overtone of the $v(\mathrm{NO})$ vibration of GS is at $2 \cdot v(\mathrm{NO})=3815 / 3801 \mathrm{~cm}^{-1}$ with a splitting of $14 \mathrm{~cm}^{-1}$ and an anharmonicity of $27 \mathrm{~cm}^{-1}$ with respect to the fundamentals. In MS1 the new bands are at $3507 / 3491 \mathrm{~cm}^{-1}$ with a splitting of $16 \mathrm{~cm}^{-1}$ but a larger anharmonicity of $33 / 35 \mathrm{~cm}^{-1}$ so that the NO-potential in MS1 is significantly broadened.

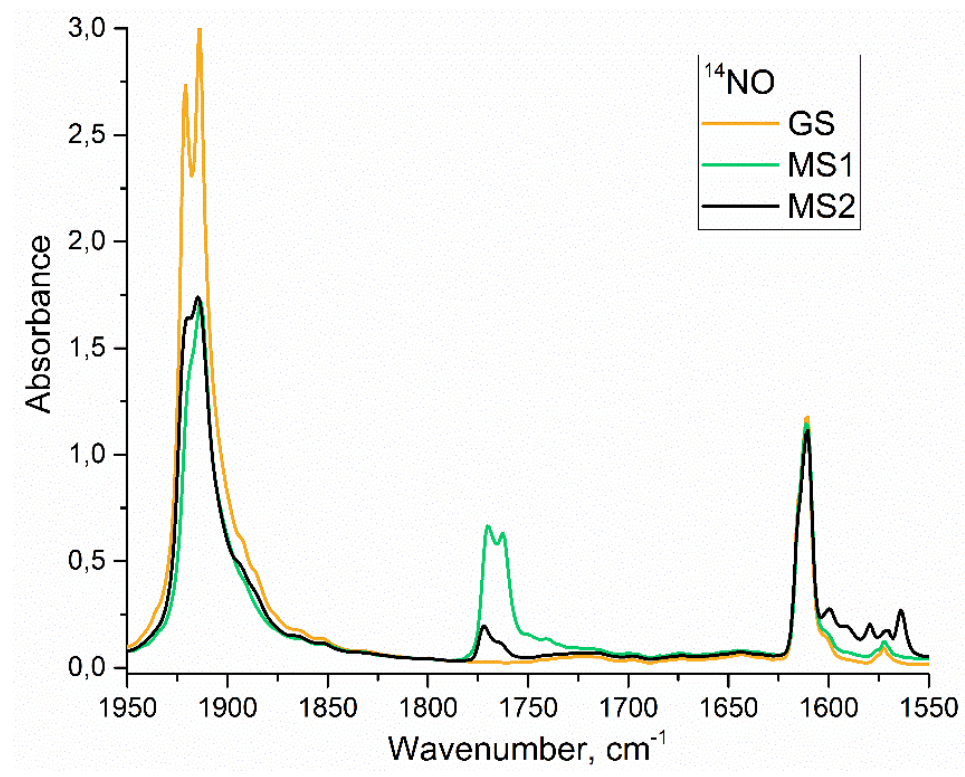

Fig. 2. The range of $1950-1550 \mathrm{~cm}^{-1}$ of IR-spectra of trans- $\left[\mathrm{Ru}\left({ }^{14} \mathrm{NO}\right)\left(\mathrm{py}_{4}\right) \mathrm{F}\right]\left(\mathrm{ClO}_{4}\right)_{2}$ in $\mathrm{GS}, \mathrm{MS} 1$ and $\mathrm{MS} 2$, $\mathrm{KBr}$ pellet.

The low-energy ranges $\left(670-400 \mathrm{~cm}^{-1}\right.$ and $\left.350-100 \mathrm{~cm}^{-1}\right)$ of the IR-spectra are shown in Figs. 3, 4 and S1-S4. For the analysis and discussion of the vibrational modes the spectrum of GS is subdivided in several regions: 1) the splitted bands at $662 / 659 / 657$ and $649 / 647 \mathrm{~cm}^{-1}$ are related to the mixed vibrations of pyridine rings and trans-ONRu-F coordinate; 2) the strongest band with maxima at $626,623 \mathrm{~cm}^{-1}$ is related to the $\delta(\mathrm{Cl}-\mathrm{O})$ vibrations of the perchlorate anion; 3 ) the band with two maxima at 563 and $558 \mathrm{~cm}^{-1}$ is related to the $v(\mathrm{Ru}-\mathrm{F})$ vibrations, the splitting is due to the two inequivalent ruthenium complexes in the crystal structure; 4) the triple band at 465, 461, $457 \mathrm{~cm}^{-}$ ${ }^{1}$ and bands at 450 and $442 \mathrm{~cm}^{-1}$, which mostly correspond to the pyridine vibrations; 5) bands with maxima at $320 / 314 / 307,277$ and $238 \mathrm{~cm}^{-1}$ comprising complex vibrations of the F-Ru-N-O chain; 6) low intense bands at 162, 143, 119 and $106 \mathrm{~cm}^{-1}$. The assignment of the bands is shown in Table 1, except of the bands below $200 \mathrm{~cm}^{-1}$.

The spectrum of MS1 shows bands at $654,611 / 605,509,480 / 473 \mathrm{~cm}^{-1}$, a triple band with maxima at 464,460 , $457 \mathrm{~cm}^{-1}$, bands at 448,441,301, 271, 231 and $147 \mathrm{~cm}^{-1}$ (not assigned), which are listed in Table 1. In case of MS2 the bands are detected at 580, 418/412/407 (the splitting is clearly visible in Fig. S3), 334, 299, 286/282, 268 and $260 \mathrm{~cm}^{-1}$ (see Table 1). All other bands are related to the pyridine rings vibrations, the bands are observed at 3119, $1611,1490,1455,1366,1249,1226,1155,1047,1017,956,769$ and $699 \mathrm{~cm}^{-1}$, which slightly change intensities after nitrosyl ligand isomerization. The visualization of the pyridine bands of the complex in GS is shown in Table S1. In addition, the intense band at $1090 \mathrm{~cm}^{-1}$ is related to the $\mathrm{v}(\mathrm{Cl}-\mathrm{O})$ stretching mode of the perchlorate anion. 


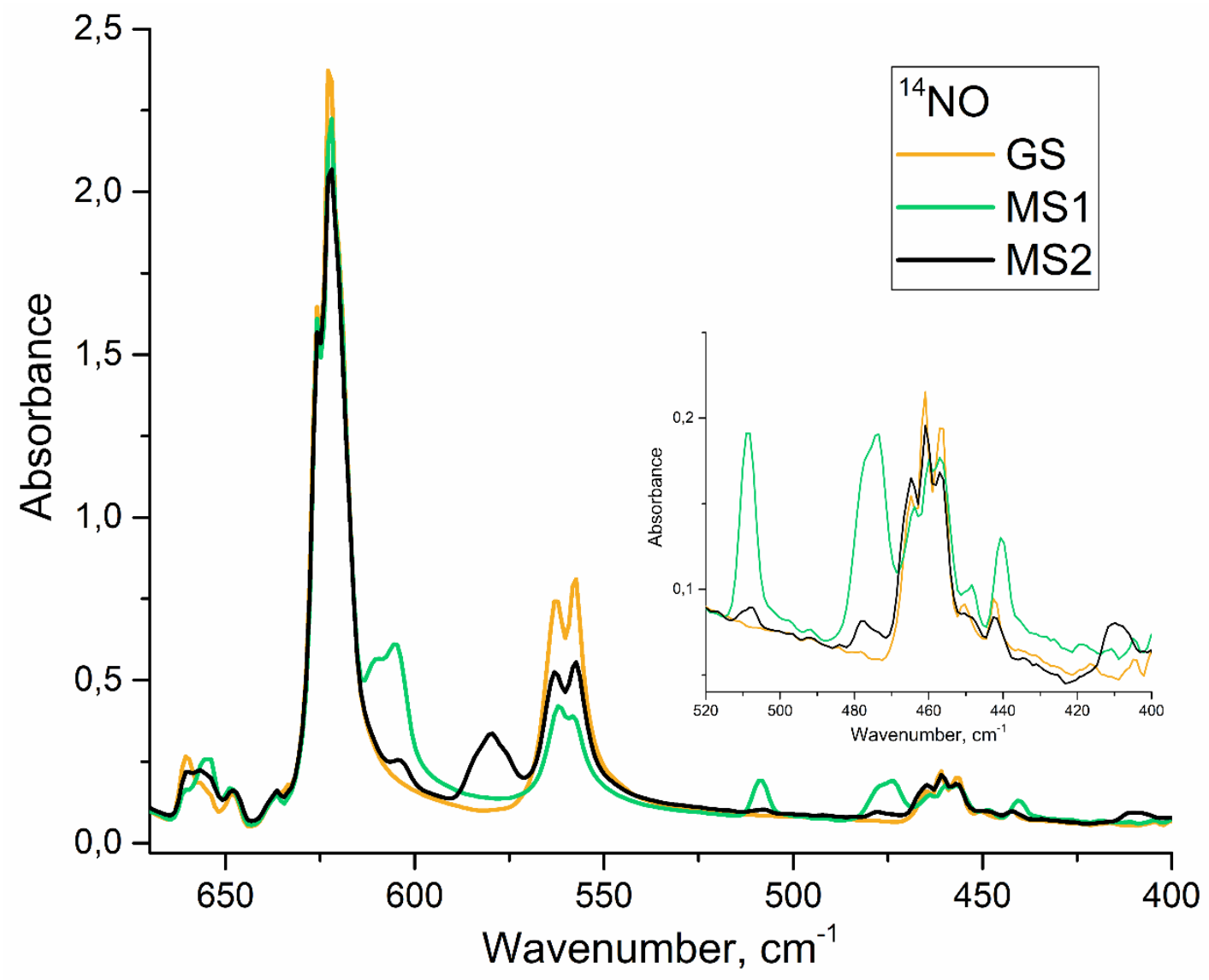

Fig. 3. The range of $670-400 \mathrm{~cm}^{-1}$ of IR-spectra of trans- $\left[\mathrm{Ru}\left({ }^{14} \mathrm{NO}\right)(\mathrm{py} 4) \mathrm{F}\right]\left(\mathrm{ClO}_{4}\right)_{2}$ in $\mathrm{GS}, \mathrm{MS} 1$ and $\mathrm{MS} 2, \mathrm{KBr}$ pellet. Insert shows the range $520-400 \mathrm{~cm}^{-1}$.
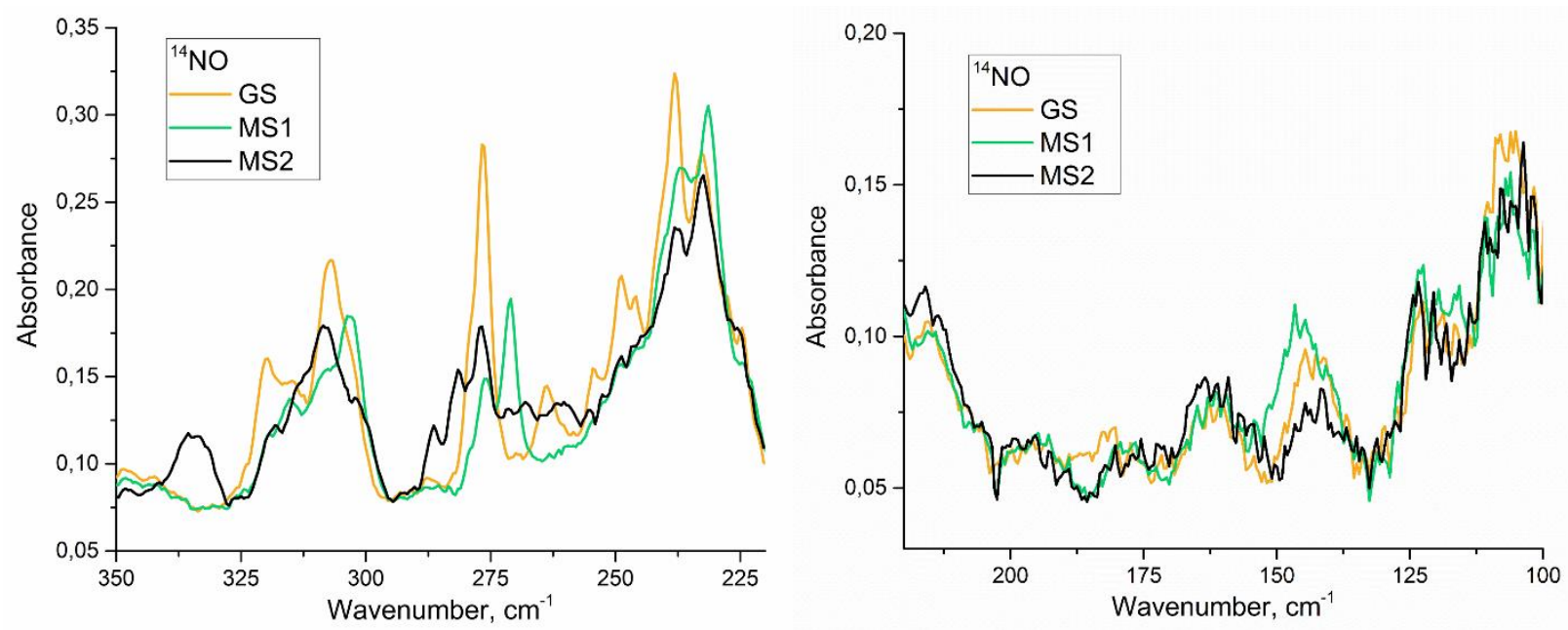

Fig. 4. The ranges of 350-200 (on the left) and 220-100 (on the right) $\mathrm{cm}^{-1}$ of IR-spectra of trans$\left[\mathrm{Ru}\left({ }^{14} \mathrm{NO}\right)\left(\mathrm{py}_{4}\right) \mathrm{F}\right]\left(\mathrm{ClO}_{4}\right)_{2}$ in GS, MS1 and MS2, PE pellet.

Table 1. The experimental (IR) and calculated (DFT, ADF, B3LYP, TZP) bands of labelled ${ }^{14} \mathrm{NO} /{ }^{15} \mathrm{NO}$ trans$\left[\mathrm{Ru}(\mathrm{NO})\left(\mathrm{py}_{4}\right) \mathrm{F}\right]\left(\mathrm{ClO}_{4}\right)_{2}$ complex in GS, MS1 and MS2 with corresponding assignment of the bands.

\begin{tabular}{|c|c|c|c|c|c|c|c|}
\hline $\begin{array}{c}\text { State/ } \\
\tilde{v}, \mathrm{~cm}^{-1}\end{array}$ & ${ }^{14} \mathrm{NO}_{\exp }$ & ${ }^{15} \mathrm{NO}_{\exp }$ & $\Delta_{\exp }$ & ${ }^{14} \mathrm{NO}_{\text {calc }}$ & ${ }^{15} \mathrm{NO}_{\text {calc }}$ & $\Delta_{\text {calc }}$ & Assignment \\
\hline
\end{tabular}




\begin{tabular}{|c|c|c|c|c|c|c|c|}
\hline \multirow{11}{*}{ GS } & $\begin{array}{l}1921 ; \\
1914\end{array}$ & $\begin{array}{l}1884 ; \\
1876\end{array}$ & $\begin{array}{c}37 ; \\
38\end{array}$ & 1916 & 1878 & 38 & $v(N O)$ \\
\hline & $\begin{array}{l}662 ; \\
659 ; \\
657\end{array}$ & $\begin{array}{l}659 ; \\
656 ; \\
654\end{array}$ & 3 & 651 & 651 & - & py $y_{\text {ring stretch }}+\delta(R u-N-O)_{m} *$ \\
\hline & - & - & - & 628 & 623 & 5 & $v\left(\right.$ Ru-NO) $+v(R u-F)_{m}$ \\
\hline & - & - & - & $\begin{array}{l}625 ; \\
623\end{array}$ & $\begin{array}{l}609 ; \\
607\end{array}$ & $\begin{array}{l}16 ; \\
16\end{array}$ & $\delta(\mathrm{Ru}-\mathrm{N}-\mathrm{O})$ \\
\hline & $\begin{array}{l}563 ; \\
558 \\
\end{array}$ & $\begin{array}{l}561 ; \\
556 \\
\end{array}$ & $\begin{array}{l}2 ; \\
2\end{array}$ & 555 & 552 & 3 & $v(R u-F)+v(R u-N O)_{m}$ \\
\hline & $\begin{array}{l}465 ; \\
461 ; \\
457\end{array}$ & $\begin{array}{l}465 ; \\
461 ; \\
457\end{array}$ & - & 445 & 445 & - & py ring bend $+\delta(\mathrm{Ru}-\mathrm{N}-\mathrm{O})_{\mathrm{m}}$ \\
\hline & 450 & 450 & - & 437 & 437 & - & py $y_{\text {ring bend }}$ \\
\hline & 442 & 442 & - & 427 & 427 & - & $p y_{\text {ring bend }}+v(\mathrm{Ru}-\mathrm{NO})_{\mathrm{m}}$ \\
\hline & $\begin{array}{c}320 \\
314 ; \\
307\end{array}$ & $\begin{array}{l}315 \\
308 \\
302\end{array}$ & $\begin{array}{l}5 ; \\
6 ; \\
5\end{array}$ & 276 & 275 & 1 & $\delta(\mathrm{F}-\mathrm{Ru}-\mathrm{N}-\mathrm{O})+\mathrm{p} \mathrm{y}_{\text {ring rocking }}$ \\
\hline & 277 & 276 & 1 & 256 & 255 & 1 & $\mathrm{v}(\mathrm{F}-\mathrm{Ru}-\mathrm{N}-\mathrm{O})+\mathrm{py} \mathrm{y}_{\text {ring rocking }}$ \\
\hline & 238 & 238 & - & 222 & 222 & - & $\delta($ Ru-F) + pyring rocking $m$ \\
\hline & & & & & & & \\
\hline \multirow{11}{*}{ MS1 } & $\begin{array}{l}1770 \\
1763\end{array}$ & $\begin{array}{l}1743 ; \\
1735\end{array}$ & $\begin{array}{l}27 ; \\
28\end{array}$ & 1871 & 1839 & 32 & $v(N O)$ \\
\hline & 654 & 654 & - & 643 & 643 & - & pyring stretch \\
\hline & $\begin{array}{l}611 ; \\
605\end{array}$ & $\begin{array}{l}611 ; \\
605\end{array}$ & - & 606 & 606 & - & $v(R u-F)$ \\
\hline & 509 & 507 & 2 & 524 & 522 & 2 & $\delta(R u-O-N)$ \\
\hline & $\begin{array}{l}480 \\
473\end{array}$ & $\begin{array}{c}473 ; \\
468\end{array}$ & $\begin{array}{l}7 ; \\
5\end{array}$ & 471 & 465 & 5 & $v(R u-O N)+v(R u-F)_{m}$ \\
\hline & $\begin{array}{l}464 ; \\
460 ; \\
457\end{array}$ & $\begin{array}{l}464 ; \\
460 ; \\
457\end{array}$ & - & 442 & 442 & - & pyring bend $+\delta(\text { Ru-O-N })_{m}$ \\
\hline & 448 & 448 & - & 438 & 438 & - & pyring bend \\
\hline & 441 & 440 & 1 & 427 & 427 & - & py ${ }_{\text {ring bend }}+v(R u-O N)_{m}$ \\
\hline & 301 & 298 & 3 & 271 & 270 & 1 & $\delta(\mathrm{F}-\mathrm{Ru}-\mathrm{O}-\mathrm{N})+\mathrm{py}_{\text {ring rocking }}$ \\
\hline & 271 & 271 & - & 246 & 245 & 1 & $\mathrm{v}(\mathrm{F}-\mathrm{Ru}-\mathrm{O}-\mathrm{N})+$ pyring rocking \\
\hline & 231 & 231 & - & 217 & 217 & - & $\delta(\mathrm{Ru}-\mathrm{F})+\mathrm{py}$ ring rocking $\mathrm{m}$ \\
\hline \multirow{9}{*}{ MS2 } & $\begin{array}{l}1600 \\
1580\end{array}$ & $\begin{array}{l}1577 ; \\
1559\end{array}$ & $\begin{array}{l}23 ; \\
21\end{array}$ & 1625 & 1597 & 28 & py $y_{\text {ring stretch }}+v(N O)_{m}$ \\
\hline & $\begin{array}{l}1591 ; \\
1564\end{array}$ & $\begin{array}{l}1565 ; \\
1541\end{array}$ & $\begin{array}{l}26 ; \\
23\end{array}$ & 1619 & 1583 & 36 & $v(N O)$ \\
\hline & - & - & - & 655 & 650 & 5 & $\delta(\mathrm{Ru}-(\mathrm{NO}))+$ pyring stretch $m$ \\
\hline & - & - & - & 636 & 626 & 9 & $\delta(\mathrm{Ru}-(\mathrm{NO}))+$ py $_{\text {ring stretch } m}$ \\
\hline & 580 & 575 & 1 & 581 & 579 & 2 & $v(\mathrm{Ru}-\mathrm{F})+\delta(\mathrm{Ru}-(\mathrm{NO}))_{\mathrm{m}}$ \\
\hline & $\begin{array}{l}418 ; \\
412 ; \\
407\end{array}$ & $\begin{array}{l}409 ; \\
406 ; \\
401\end{array}$ & $\begin{array}{l}9 ; \\
6 ; \\
6\end{array}$ & 410 & 408 & 2 & $v(\mathrm{Ru}-(\mathrm{NO}))$ \\
\hline & 334 & 332 & 2 & 298 & 298 & - & $\delta(\mathrm{F}-\mathrm{Ru}-(\mathrm{NO}))_{\perp}+\mathrm{py}_{\text {ring rocking }}$ \\
\hline & 299 & 299 & - & 271 & 271 & - & $\delta(\mathrm{F}-\mathrm{Ru}-(\mathrm{NO}))+\mathrm{py}_{\text {ring rocking }}$ \\
\hline & $\begin{array}{l}286 \\
282\end{array}$ & $\begin{array}{l}285 \\
281\end{array}$ & 1 & 256 & 255 & 1 & $v(R u-(N O))+\delta(R u-F)+p y_{\text {ring rocking }}$ \\
\hline
\end{tabular}




\begin{tabular}{|l|c|c|c|c|c|c|c|}
\hline & 268 & 268 & - & 244 & 244 & - & $\delta(\mathrm{Ru}-\mathrm{F})+$ py ring rocking $\mathrm{m}$ \\
\cline { 2 - 8 } & 260 & 259 & 1 & 232 & 231 & 1 & $\delta(\mathrm{Ru}-(\mathrm{NO}))_{\perp}+\delta(\mathrm{Ru}-\mathrm{F})$ \\
\hline
\end{tabular}

\section{IR-spectra of trans-[Ru( $\left.\left.{ }^{15} \mathrm{NO}\right)(\mathrm{py})_{4} \mathrm{~F}\right](\mathrm{ClO} 4)_{2}$}

The irradiation of the ${ }^{15} \mathrm{NO}$ labelled complex induces analogous changes in the spectra (see Fig. 5 and Table 1). The labelling of the complex by the ${ }^{15} \mathrm{NO}$ shifts the $\mathrm{v}(\mathrm{NO})$ bands to lower wavenumbers, which is in agreement with earlier reports [40]. The shift of the GS, MS1 and MS2 bands is $37 / 38,27 / 28$ and $23 / 21 / 26 / 23 \mathrm{~cm}^{-1}$, respectively. The different values of the shifts are related to the different coordination type of the NO ligand, a larger isotope effect might indeed be expected for the nitrogen bound GS configuration, compared to the oxygen bound MS1 configuration.

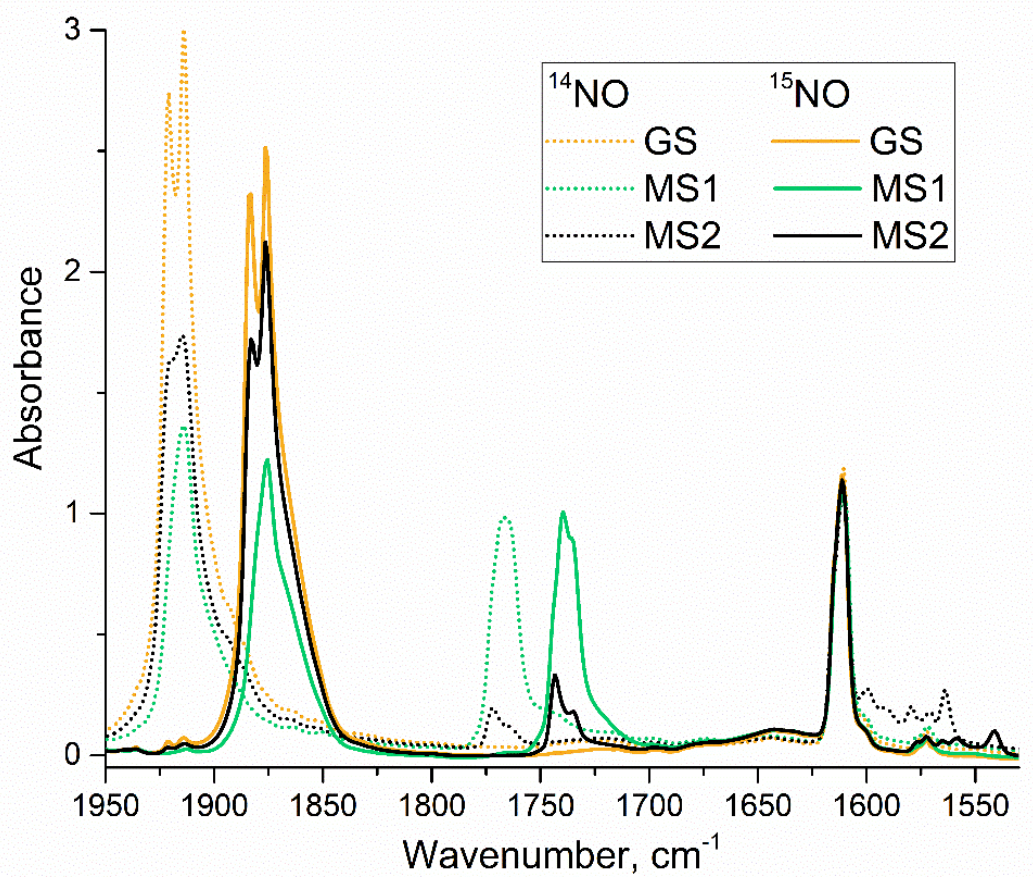

Fig. 5. The range of $1950-1550 \mathrm{~cm}^{-1}$ of IR-spectra of trans $-\left[\mathrm{Ru}\left({ }^{15} \mathrm{NO}\right)(\mathrm{py})_{4} \mathrm{~F}\right]\left(\mathrm{ClO}_{4}\right)_{2}$ in GS, MS1 and MS2 (solid lines) and corresponding data of trans-[Ru( $\left.\left({ }^{14} \mathrm{NO}\right)(\mathrm{py})_{4} \mathrm{~F}\right]\left(\mathrm{ClO}_{4}\right)_{2}$ (dotted lines), $\mathrm{KBr}$ pellet.

The isotope-induced wavenumber shifts in the low-energy range of the spectra are extremely helpful for an unambiguous assignment of the bands (see Figs. 6,7 and S1-S3). From the literature data $[35,40]$, the labelling of the species by the ${ }^{15} \mathrm{NO}$ induces a shift of the $\delta(\mathrm{Ru}-\mathrm{N}-\mathrm{O})$ and $v(\mathrm{Ru}-\mathrm{NO})$ modes by $\sim 15$ and $\sim 5 \mathrm{~cm}^{-1}$ respectively to lower energy. In the GS there are only four bands at 659/656/654, 561/556, 315/308/302 and $276 \mathrm{~cm}^{-1}$ which show isotopic shift (see Table 1). The band at $140 \mathrm{~cm}^{-1}$ probably also exhibits an isotopic shift, however its low intensity prevents a definitive conclusion. In the case of MS1, four bands at 507, 473/468, 440 and $298 \mathrm{~cm}^{-1}$ indicate isotopic shift by $1,7 / 5,1$ and $3 \mathrm{~cm}^{-1}$, respectively. Similar to the band of GS at $140 \mathrm{~cm}^{-1}$, the band of MS1 at $143 \mathrm{~cm}^{-1}$ may show isotopic shift (see Fig. 7). Finally, in MS2 the isotopic shift is observed for bands at 575, 409/406/401, 332, $285 / 281$ and $259 \mathrm{~cm}^{-1}$ with shifts by $1-9 \mathrm{~cm}^{-1}$ (see Table 1 ). The shift of the listed bands clearly indicates the presence of $v(\mathrm{Ru}-(\mathrm{NO}))$ and/or $\delta(\mathrm{Ru}-(\mathrm{N}-\mathrm{O}))$ modes in these bands. If the observed bands would correspond to pure vibrational modes of one species, as often assumed for simplification in the discussions found in the literature, one would expect isotope-induced changes only for the $v(\mathrm{Ru}-\mathrm{NO})$ and $\delta(\mathrm{Ru}-(\mathrm{N}-\mathrm{O}))$ modes. However, the real situation is more complex including coupling of vibrational modes and hence fractional contributions of certain modes to several bands. In order to give an accurate and unambiguous assignment in these circumstances, we use the DFT calculated values for the assignment. 


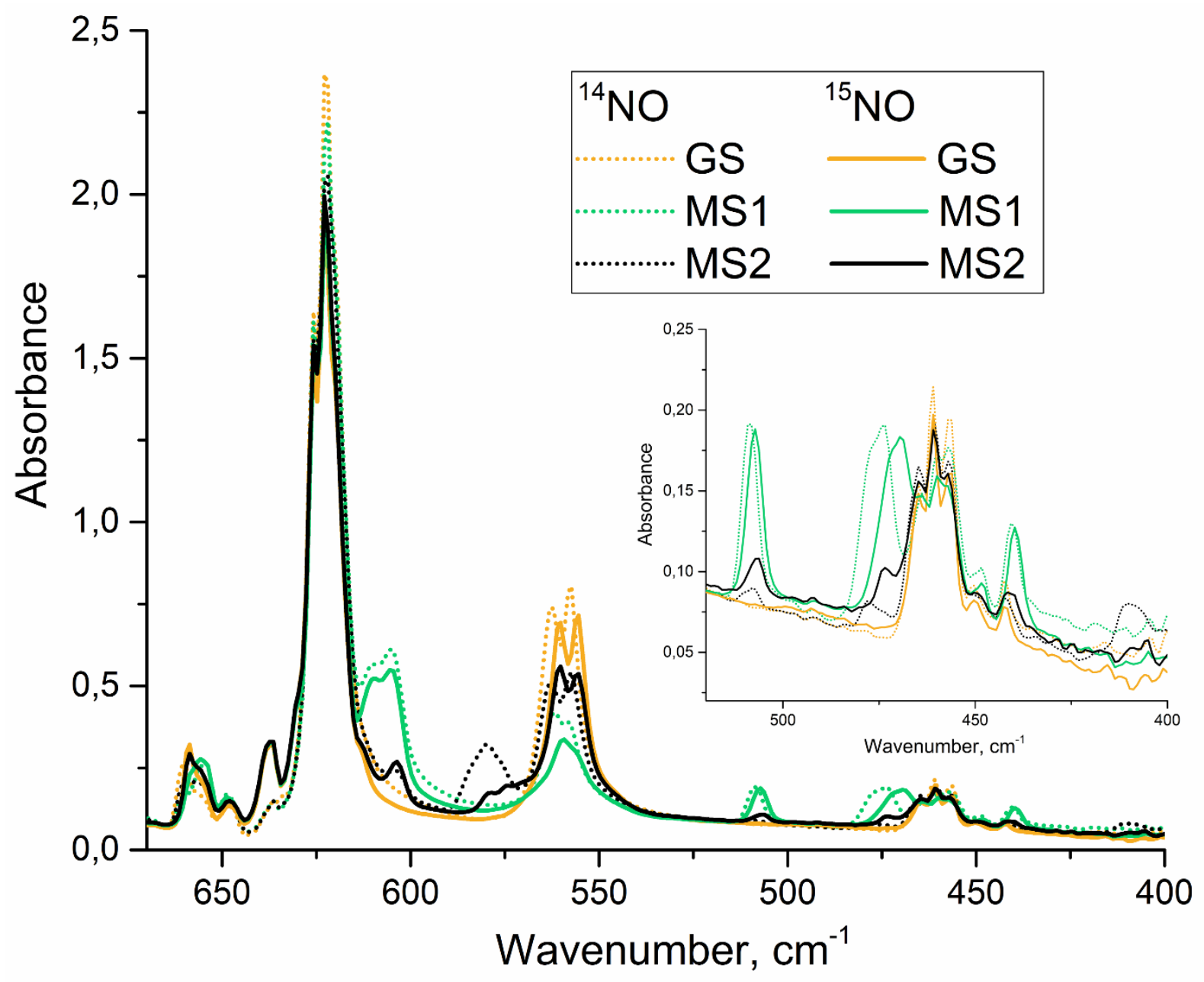

Fig. 6. The range of $670-400 \mathrm{~cm}^{-1}$ of IR-spectra of trans- $\left[\mathrm{Ru}\left({ }^{15} \mathrm{NO}\right)(\mathrm{py})_{4} \mathrm{~F}\right]\left(\mathrm{ClO}_{4}\right)_{2}$ in $\mathrm{GS}$, MS1 and MS2 (solid lines) and corresponding data of trans- $\left[\mathrm{Ru}\left({ }^{14} \mathrm{NO}\right)(\mathrm{py})_{4} \mathrm{~F}\right]\left(\mathrm{ClO}_{4}\right)_{2}$ (dotted lines), $\mathrm{KBr}$ pellet. Insert shows the range $520-400 \mathrm{~cm}^{-1}$.
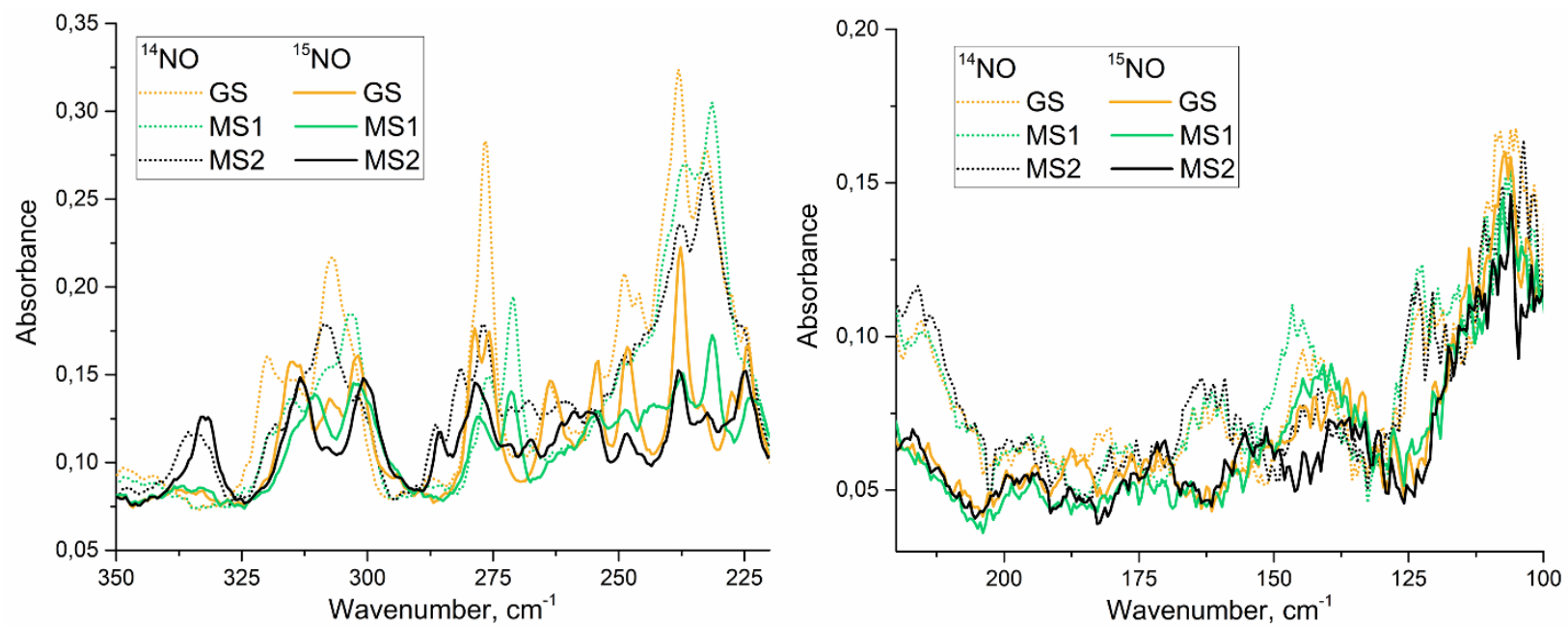

Fig. 7. The ranges of 350-200 (on the left) and 220-100 (on the right) $\mathrm{cm}^{-1}$ of IR-spectra of trans$\left[\mathrm{Ru}\left({ }^{15} \mathrm{NO}\right)(\mathrm{py})_{4} \mathrm{~F}\right]\left(\mathrm{ClO}_{4}\right)_{2}$ in GS, MS1 and MS2 (solid lines) and corresponding data of trans$\left[\mathrm{Ru}\left({ }^{14} \mathrm{NO}\right)(\mathrm{py})_{4} \mathrm{~F}\right]\left(\mathrm{ClO}_{4}\right)_{2}$ (dotted lines), PE pellet. 


\section{DFT calculations of ${ }^{14} \mathrm{NO} /{ }^{15} \mathrm{NO}$ complexes}

The IR frequencies calculated by DFT are in good agreement with the experimental data, the differences in the experimental and calculated frequencies of the $v / \delta(\mathrm{ON}-\mathrm{Ru}-\mathrm{F})$ vibrations do not exceed $36 \mathrm{~cm}^{-1}$. However, the calculated energies of the $v(\mathrm{NO})$ bands of the metastable states (mostly for MS1) are overestimated, which is probably due to worse convergence of the optimized geometries with respect to the GS structure (see Table S2 and Fig. 1), and because the crystal environment is neglected in the used model (gas phase, trans $-\left[\mathrm{Ru}(\mathrm{NO})(\mathrm{py}){ }_{4} \mathrm{~F}\right]^{2+}$ ion). Nevertheless, the DFT calculations provide a full picture of the atomic movements, intensities of the vibrational bands and the wavenumbers in order to assign the observed bands to the associated atomic movements. The calculated high-energy range of the spectra is shown in Fig. 8. The v(NO) bands of the GS and MS1 exhibit a similar downshift with respect to the experimental data (see Table 1). The isotopic shifts of the bands are 38 and $32 \mathrm{~cm}^{-1}$, respectively, with a small overestimation of the shift in case of MS1. The spectra of MS2 contains two bands of $v(N O)$ stretching vibration: one intense band at $1619 \mathrm{~cm}^{-1}$ with isotopic shift of $36 \mathrm{~cm}^{-1}$ and the second band at 1625 $\mathrm{cm}^{-1}$ with a smaller shift of $28 \mathrm{~cm}^{-1}$. The second band reveals mixed vibrations of $\mathrm{v}(\mathrm{NO})$ and stretching vibration of the pyridine ring (see visualization of displacements vectors in Fig. S5). Apparently, the split is due to both the elongation of the Ru-(NO) bond length and the side-on bond coordination type of the nitrosyl, which induce such intramolecular interaction. In the experimental data the isotopic shifts for these bands are $23 / 21$ and $26 / 23 \mathrm{~cm}^{-1}$, so the agreement between experiment and calculation is reasonable.

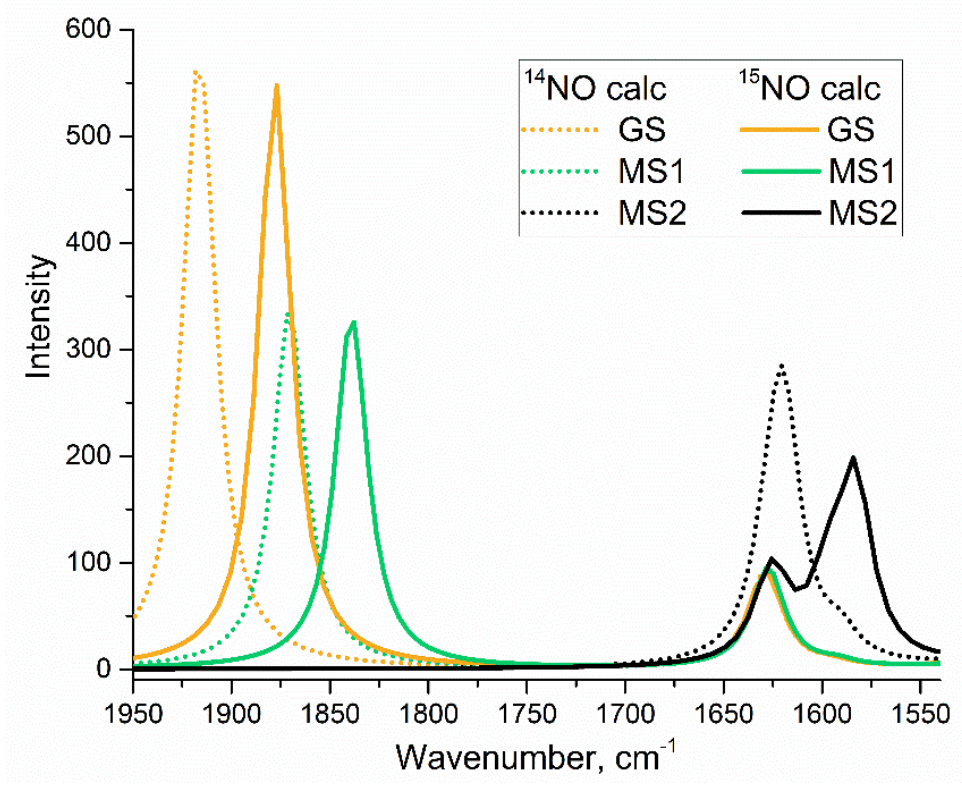

Fig. 8. The range of $1950-1550 \mathrm{~cm}^{-1}$ of DFT (ADF, B3LYP, TZP) calculated IR-spectra of trans$\left[\mathrm{Ru}\left({ }^{15} \mathrm{NO}\right)(\mathrm{py})_{4} \mathrm{~F}\right]^{2+}$ in GS, MS1 and MS2 (solid lines) and corresponding data of trans-[Ru( $\left.\left.\left.{ }^{14} \mathrm{NO}\right)(\mathrm{py}){ }_{4} \mathrm{~F}\right]\right]^{2+}$ (dotted lines).

The low-energy range of the calculated spectra is shown in Fig. 9. The calculated spectrum of the GS exhibit assigned bands at $651,648,628,625 / 623,555,445,437,427,276,256$ and $222 \mathrm{~cm}^{-1}$. The bands at 651 and $648 \mathrm{~cm}^{-}$ ${ }^{1}$ do not show significant isotopic shift (the isotopic shift for the band at $651 \mathrm{~cm}^{-1}$ is $0.4 \mathrm{~cm}^{-1}$ ), however the band at $651 \mathrm{~cm}^{-1}$ contains mixed vibrations of stretching type of pyridine rings and a smaller fraction of $\delta(\mathrm{Ru}-\mathrm{N}-\mathrm{O})$ bending vibration (see Fig. $\mathrm{S} 6$ with visualizations). So, it is likely to see the isotopic shift in the experimental spectra, namely in the band at $662 / 659 / 657 \mathrm{~cm}^{-1}$. The bands at 628 and $625 / 623 \mathrm{~cm}^{-1}$ have characteristic isotopic shifts $[35,40]$ and correspond to the $v(\mathrm{Ru}-\mathrm{NO})$ and $\delta(\mathrm{Ru}-\mathrm{N}-\mathrm{O})$ modes. Unfortunately, the intense bands of $\delta(\mathrm{Cl}-\mathrm{O})$ prevent the experimental detection of these weak bands. The band at $555 \mathrm{~cm}^{-1}$ shows isotopic shift and is related to the mixed vibrations of $v(R u-F)$ with a moderate contribution of the $v(R u-N O)$ mode. The band at $445 \mathrm{~cm}^{-1}$ does not exhibit an isotopic shift and is assigned to the bending vibration of the pyridine ligands with very small contribution of $\delta(\mathrm{Ru}-$ 
$\mathrm{N}-0$ ). Most likely, this band is related to the triple band at $465,461,457 \mathrm{~cm}^{-1}$ in the experimental spectrum, where the observed splitting is due to the two different ruthenium complexes in the crystal structure. The band at $437 \mathrm{~cm}^{-}$ ${ }^{1}$ is assigned to the pure bending vibration of the pyridine ligands, whereas the band at $427 \mathrm{~cm}^{-1}$ also comprises a very small contribution of the $\mathrm{v}(\mathrm{Ru}-\mathrm{NO})$ mode. In the calculated spectrum three intense bands were observed at 276,256 and $222 \mathrm{~cm}^{-1}$ in the range of $400-200 \mathrm{~cm}^{-1}$, which were assigned to the most intense bands of the experimental spectra. The bands at 276 and $256 \mathrm{~cm}^{-1}$ show isotopic shifts similar to the ones observed in the experimental data and are related to the "deformational» $\delta(\mathrm{F}-\mathrm{Ru}-\mathrm{N}-\mathrm{O})$ and «stretching» v(F-Ru-N-O) vibrations of the whole linear chain F-Ru-N-O with a considerable displacement vector of the ruthenium atom (see Fig. S7 with visualizations). These bands also comprise moderate contributions of «wheel-like» vibrations of the pyridine rings (pyring rocking). The band at $222 \mathrm{~cm}^{-1}$ reflects the $\delta(R u-F)$ vibration with contribution of the pyring rocking. Note that the assignment of the bands below $200 \mathrm{~cm}^{-1}$ is very tentatively due to the low resolution and intensity of experimental bands in that range, and will not be discussed further. In conclusion, all experimental bands of GS, which show significant isotopic shift, truly contain the contributions from the $v(\mathrm{Ru}-\mathrm{NO})$ and $\delta(\mathrm{Ru}-\mathrm{N}-\mathrm{O})$ vibrational modes, which is verified by the calculations and in good agreement with DFT data.

The spectra of MS1 contain six bands at $643,606,442,438$ and $427 \mathrm{~cm}^{-1}$, which do not show an isotopic shift. The band at $643 \mathrm{~cm}^{-1}$ is assigned to the stretching vibration of pyridine rings, whereas the band at $606 \mathrm{~cm}^{-1}$ corresponds to the pure stretching vibration v(Ru-F) (see Fig. S6). The band at $442 \mathrm{~cm}^{-1}$ comprises bending vibrations of pyridines with small partial contribution of $\delta\left(\right.$ Ru-O-N). Similar to the triple band of GS, the band at $442 \mathrm{~cm}^{-1}$ corresponds to the triple band with maxima at $464,460,457 \mathrm{~cm}^{-1}$ in the experimental spectrum. The band at 438 $\mathrm{cm}^{-1}$ is related to the bending vibrations of pyridine, and the band at $427 \mathrm{~cm}^{-1}$ additionally comprises small contribution of $v(\mathrm{Ru}-\mathrm{NO})$, which agrees with experimental data, where the band exhibits an isotopic shift of $1 \mathrm{~cm}^{-1}$ (see Table 1). The band at $217 \mathrm{~cm}^{-1}$ is assigned to the $\delta(R u-F)$ vibration with partial contribution of the pyring rocking vibration. The bands at 524 and $471 \mathrm{~cm}^{-1}$ show isotopic shifts of 2 and $5 \mathrm{~cm}^{-1}$, respectively, and correspond to the $\delta(\mathrm{Ru}-\mathrm{O}-\mathrm{N})$ and $v(\mathrm{Ru}-\mathrm{ON})$ modes. The latter vibration comprises small contribution from the $v(\mathrm{Ru}-\mathrm{F})$ mode. Similarly, bands at 271 and $246 \mathrm{~cm}^{-1}$ exhibit isotopic shift by $1 \mathrm{~cm}^{-1}$ and correspond to the $\delta(\mathrm{F}-\mathrm{Ru}-\mathrm{O}-\mathrm{N})$ and $\mathrm{v}(\mathrm{F}-\mathrm{Ru}-\mathrm{N}-\mathrm{O})$ vibrations of the F-Ru-O-N chain with a contribution of pyring rocking (see Fig. S7). The experimental isotopic shift of the band at $271 \mathrm{~cm}^{-1}\left(246 \mathrm{~cm}^{-1}\right.$ in calculation $)$ is $0.4 \mathrm{~cm}^{-1}$.

Similar to the experimental data, in the calculated spectra of MS2 the bands at 581 and $410 \mathrm{~cm}^{-1}$ show isotopic shifts of $2 \mathrm{~cm}^{-1}$. The band at $581 \mathrm{~cm}^{-1}$ reveals the mixed vibration of $v(\mathrm{Ru}-\mathrm{F})$ with partial contribution of $\delta(\mathrm{Ru}-(\mathrm{N}-\mathrm{O}))$ mode, whereas the band at $410 \mathrm{~cm}^{-1}$ is assigned to the $v(\mathrm{Ru}-(\mathrm{NO})$ ) vibration (see visualization in Fig. S8). Also, the two calculated bands at 655 and $636 \mathrm{~cm}^{-1}$ exhibit significant isotopic shifts by 5 and $9 \mathrm{~cm}^{-1}$ respectively. Both bands correspond to the $\delta(\mathrm{Ru}-(\mathrm{NO}))$ vibrations mixed with the stretching vibrations of pyridine rings. These bands are not visible in the experimental spectra due to the presence of the intense $\delta(\mathrm{Cl}-\mathrm{O})$ band in the same region. The spectrum of MS2 below $400 \mathrm{~cm}^{-1}$ exhibits at least five dominant vibrations. Similar to GS and MS1, the bands at 271, 256 and $244 \mathrm{~cm}^{-1}$ are assigned to the $\delta(\mathrm{F}-\mathrm{Ru}-(\mathrm{NO}))$, combined $v(\mathrm{Ru}-(\mathrm{NO})) / \delta(\mathrm{Ru}-\mathrm{F})$ and single $\delta(\mathrm{Ru}-\mathrm{F})$ vibrations, respectively, with contribution of the pyring rocking for all bands. An isotopic shift is observed for the band at $256 \mathrm{~cm}^{-1}$, similar to the experimental data (band at $286 / 282 \mathrm{~cm}^{-1}$ ). The band at $271 \mathrm{~cm}^{-1}$ exhibits an isotopic shift of $0.4 \mathrm{~cm}^{-1}$, whereas the experimental detection of the shift is limited by the low intensity of the band $\left(299 \mathrm{~cm}^{-1}\right)$. The remaining two bands at 298 and $232 \mathrm{~cm}^{-1}$ involve a different vibrational type of NO, for which the displacement vectors are directed perpendicular to the F-Ru-(NO) chain (see Fig. S7). Thus, the band at $298 \mathrm{~cm}^{-1}$ is assigned to the $\delta(\mathrm{F}-\mathrm{Ru}-(\mathrm{NO}))_{\perp}$ mode and comprises pyring rocking vibration. Experimentally, the band shows an isotopic shift of $2 \mathrm{~cm}^{-1}$, which can be expected due to the presence of the bending mode of NO. The band at $232 \mathrm{~cm}^{-1}$ shows an isotopic shift and is assigned to the mixed vibrations of $\delta(\mathrm{Ru}-(\mathrm{NO}))_{\perp}$ and $\delta(\mathrm{Ru}-\mathrm{F})$, in view of the absence of a displacement vector on the ruthenium atom. Hence, the special coordination of the NO ligand in MS2 generates completely new vibrational modes leading to the appearance of the new bands in the spectra.

In order to assess the reliability of the calculated data, additional independent structure optimization and calculation of IR spectra for GS, MS1 and MS2 of trans $-\left[\mathrm{Ru}\left({ }^{14} \mathrm{NO}\right)(\mathrm{py})_{4} \mathrm{~F}\right]^{2+}$ were performed using the CASTEP code 
[55] applying methods based on plane-wave basis sets and pseudopotentials. The obtained frequencies are summarized in Table S3, which show reasonable agreement with the experimental and ADF calculated data.
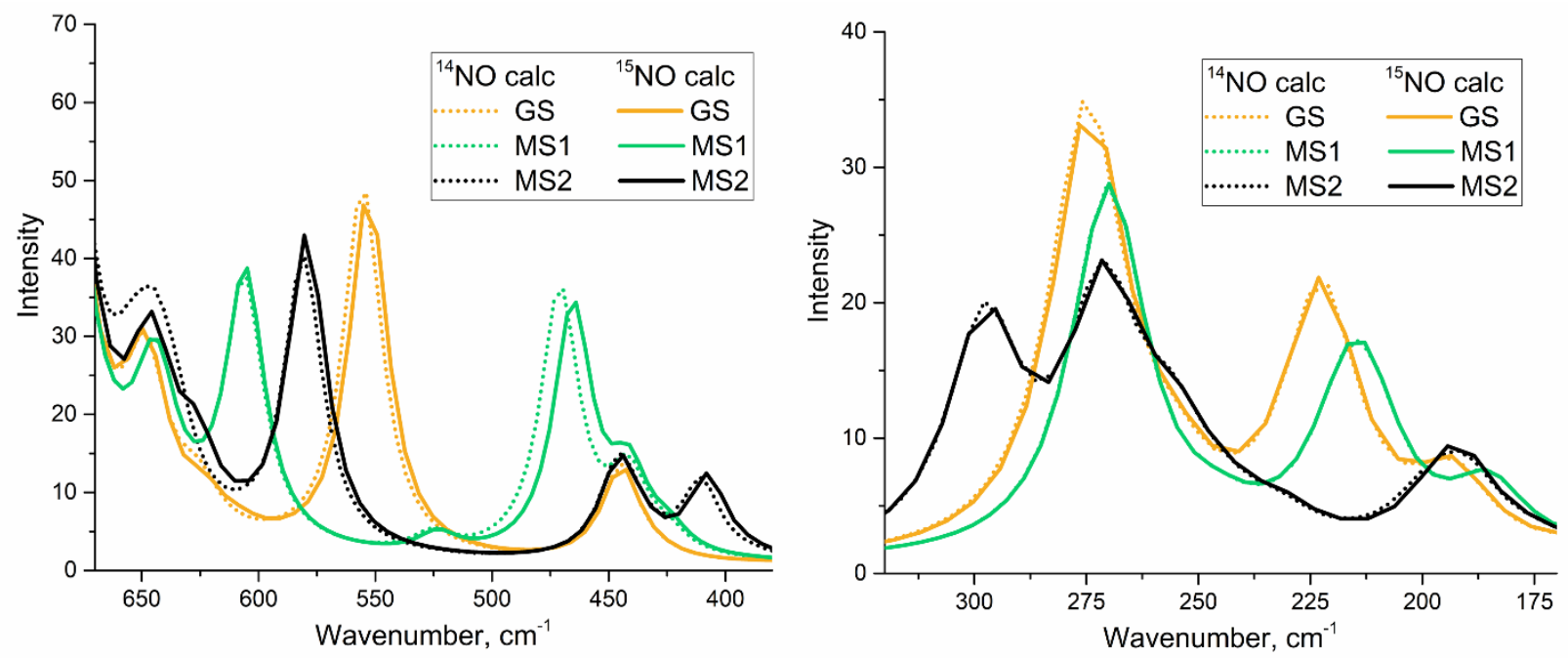

Fig. 9. The ranges of $670-400$ (on the left) and 350-170 (on the right) $\mathrm{cm}^{-1}$ of DFT (ADF, B3LYP, TZP) calculated IR-spectra of trans- $\left.\left[\mathrm{Ru}\left({ }^{15} \mathrm{NO}\right)(\mathrm{py}){ }_{4} \mathrm{~F}\right]\right]^{2+}$ in GS, MS1 and MS2 (solid lines) and corresponding data of trans- $\left[\mathrm{Ru}\left({ }^{14} \mathrm{NO}\right)(\mathrm{py})_{4} \mathrm{~F}\right]^{2+}$ (dotted lines).

Thus, based on the DFT models we can unambiguously assign all experimental bands showing the features of linkage isomers. First of all, the calculated $v(N O)$ band of MS2 shows the splitting of this band and thus explains the experimental observation. While this effect may be characteristic only for pyridine complexes we cannot exclude that the particular structural configuration of MS2 would lead to similar observations for the whole family of these nitrosyl complexes, which show the formation of MS2 isomer. It is important to mention, that usually the population of MS2 is low, which renders the experimental detection of the corresponding bands more difficult. From the calculations we can derive the major vibrational contributions and assign them to the observed bands. In GS, the vibrations $v(\mathrm{Ru}-\mathrm{NO})$ and $v(\mathrm{Ru}-\mathrm{F})$ are not completely separated due to combined movements, however, in regard of the dominant contributions, the $v(\mathrm{Ru}-\mathrm{F})$ mode has lower energy $\left(563 / 558 \mathrm{~cm}^{-1}\right.$, exp.) with respect to the $v(\mathrm{Ru}-\mathrm{NO})$ mode $\left(628 \mathrm{~cm}^{-1}\right.$, calc.). The $\delta(\mathrm{Ru}-\mathrm{N}-\mathrm{O})$ mode possesses almost the same energy $\left(625 / 623 \mathrm{~cm}^{-1}\right.$, calc.) as $v(\mathrm{Ru}-\mathrm{NO})$, which is likely a specific feature of this complex which cannot be generalized. The energy gap between $\delta(\mathrm{F}-\mathrm{Ru}-\mathrm{N}-\mathrm{O})$ $\left(320 / 314 / 307 \mathrm{~cm}^{-1}\right)$ and $v(\mathrm{~F}-\mathrm{Ru}-\mathrm{N}-\mathrm{O})\left(277 \mathrm{~cm}^{-1}\right)$ is with $40 \mathrm{~cm}^{-1}$ more pronounced. An even bigger difference is found for the $v(R u-F)$ and $\delta(R u-F)\left(228 \mathrm{~cm}^{-1}\right)$ vibrations, with a gap of $330 \mathrm{~cm}^{-1}$. In case of MS1, the elongation of the RuON bond length mediates the split of the $v(R u-N O) / v(R u-F)$ modes. The pure $v(R u-F)\left(611 / 605 \mathrm{~cm}^{-1}\right)$ stretching mode is shifted by $47 \mathrm{~cm}^{-1}$ to higher energy with respect to the same band of GS, which is in accordance with the experimental Ru-F bond lengths (1.914 $\AA$ in GS vs. $1.898 \AA$ in MS1). The opposite situation is observed for the calculated $v\left(\right.$ Ru-ON) and $\delta\left(\right.$ Ru-O-N) modes, which are shifted to lower energy by 157 and $101 \mathrm{~cm}^{-1}$ respectively. Thus, in MS1 the energy of the $\delta(\mathrm{Ru}-\mathrm{O}-\mathrm{N})$ mode $\left(509 \mathrm{~cm}^{-1}\right)$ is higher than the energy of the $v(\mathrm{Ru}-\mathrm{ON})$ mode $(480 / 473$ $\mathrm{cm}^{-1}$ ). Note, that the experimental bond lengths for Ru-NO and Ru-ON are 1.750 and $1.841 \AA$, respectively. A similar sequence is conserved for the $\delta(F-R u-O-N)\left(301 \mathrm{~cm}^{-1}\right)$ and v(F-Ru-O-N) $\left(271 \mathrm{~cm}^{-1}\right)$, with an energy gap of $33 \mathrm{~cm}^{-1}$. Interestingly, contrary to the energy of the $v(R u-F)$ mode, the energy of the $\delta(R u-F)$ mode of MS1 $\left(231 \mathrm{~cm}^{-1}\right)$ is lower with respect to that for $\mathrm{GS}\left(238 \mathrm{~cm}^{-1}\right)$. Apparently, such a behavior is due to a larger influence of $\mathrm{py}_{\text {ring rocking vibrations }}$ to these bands. Similar to MS1, the $v(R u-F)$ band of MS2 is shifted to higher energy with respect to $G S$ by $17 \mathrm{~cm}^{-1}$. Clearly, the shift reflects the contraction of the Ru- $\mathrm{F}$ bond length, supported by the calculations and $\mathrm{X}$-ray diffraction results obtained for the related trans-[Ru(NO)(py) $\left.{ }_{4} \mathrm{Cl}\right]\left(\mathrm{PF}_{6}\right)_{2} \cdot 0.5 \mathrm{H}_{2} \mathrm{O}[31]$. The $v(\mathrm{Ru}-(\mathrm{NO}))$ vibration is also shifted to lower energy by $218 \mathrm{~cm}^{-1}$, due to large difference in the Ru-(NO) bond length compared to GS. The correlation between the calculated bond lengths Ru-(NO), Ru-F and the wavenumbers of $v(R u-(N O)), v(R u-F)$ shows a linear behavior as illustrated by the fit given in Fig. S9. The $\delta(\mathrm{Ru}-(\mathrm{NO}))$ bands of MS2 are found at almost the same position as the $\delta(\mathrm{Ru}-\mathrm{N}-\mathrm{O})$ bands of GS (655/636 in MS2 vs. 625/623 in GS). Although the MS2 and GS bands are close energy, it is important to emphasize that MS2 possesses a completely different coordination type of NO. This fact is 
especially reflected by the appearance of new bands, which are different from those of GS and MS1, namely the $\delta(\text { Ru-(NO) })_{\perp}$ modes. Finally, the energy of $\delta(R u-F)\left(268 \mathrm{~cm}^{-1}\right)$ of MS2 is higher than that of GS $\left(238 \mathrm{~cm}^{-1}\right)$ and MS1 $\left(231 \mathrm{~cm}^{-1}\right)$, whereby no correlation is observed with respect to the Ru-F bond length. Presumably, the absence of such a correlation in the range of $400-200 \mathrm{~cm}^{-1}$ is due to a bigger contribution of pyring rocking vibrations to the bands in this spectral region.

\section{The $\mathrm{N}_{2} \mathrm{O}$ release in $\mathrm{KBr}$ pellets}

The long-time irradiation (130 min vs. 10 min characteristic for previous chapter) of the complex induces the formation of the bands at 2228 and $2159 \mathrm{~cm}^{-1}$ in case of ${ }^{14} \mathrm{NO}$ and ${ }^{15} \mathrm{NO}$ species respectively (Fig. 10). On the one hand, these bands may reflect the formation of free nitrous oxide $\mathrm{N}_{2} \mathrm{O}(\mathrm{v}(\mathrm{N}-\mathrm{N})$ vibration), which have similar signatures depending on the crystallinity of the $\mathrm{N}_{2} \mathrm{O}$ phase $[58,59]$. On the other hand, the coordinated $\mathrm{N}_{2} \mathrm{O}$ ligand exhibits a similar band at $2231 \mathrm{~cm}^{-1}$, however its isotopic shift (labelling by ${ }^{15} \mathrm{~N}_{2} \mathrm{O}$ ) was found at $2209 \mathrm{~cm}^{-1}(\Delta$ of free $\mathrm{N}_{2} \mathrm{O}$ is $69 \mathrm{~cm}^{-1}$ vs. $\Delta$ of coord. $\mathrm{N}_{2} \mathrm{O}$ is $22 \mathrm{~cm}^{-1}$ ) [41]. Such kind of bands of ${ }^{14} \mathrm{~N}_{2} \mathrm{O}$ and ${ }^{15} \mathrm{~N}_{2} \mathrm{O}$ were observed at 2226 and $2157 \mathrm{~cm}^{-1}$ after photolysis of a dimeric hyponitrite complex $\left[\left(\mathrm{NH}_{3}\right)_{5} \mathrm{CoN}(\mathrm{O}) \mathrm{NOCo}\left(\mathrm{NH}_{3}\right)_{5}\right] \mathrm{Br}_{4}$ in the solid state [60]. The bands were assigned to the coordinated $\mathrm{N}_{2} \mathrm{O}$ ligand. In our case we rather suggest the formation of free $\mathrm{N}_{2} \mathrm{O}$, given that a smaller isotopic shift would be expected in the case of coordinated $\mathrm{N}_{2} \mathrm{O}$ [41]. Nevertheless, in the absence of reference data for a coordinated $\mathrm{Ru}-\mathrm{N}_{2} \mathrm{O}$ compound, we cannot unambiguously exclude that the detected vibrational mode belongs to a coordination state of $\mathrm{N}_{2} \mathrm{O}$. The formation of a complex with coordinated dinitrogen $\mathrm{N}_{2}$ can be ruled out due to the fact that the $\mathrm{v}(\mathrm{N}-\mathrm{N})$ band would be expected at much lower wavenumbers $\left(\approx 2100 \mathrm{~cm}^{-1}\right)$ [61]. Based on the decrease of the intensity of the $v(\mathrm{NO})$ band after irradiation, trans$\left[\mathrm{Ru}(\mathrm{NO})(\mathrm{py})_{4} \mathrm{~F}\right]\left(\mathrm{ClO}_{4}\right)_{2}$ loses about $20 \%$ of $\mathrm{NO}$ upon long-time irradiation in the blue-violet spectral range. Earlier reports suggested the photoinduced release of $\mathrm{N}_{2} \mathrm{O}$ or $\mathrm{NO}$ in solid state [47-49], while our current results (including isotope labelling) rather support the formation of $\mathrm{N}_{2} \mathrm{O}$ in $\mathrm{KBr}$. Such a product would indicate a high reactivity of the coordinated $\mathrm{NO}$ in $\mathrm{KBr}$ pellets even at $10 \mathrm{~K}$.

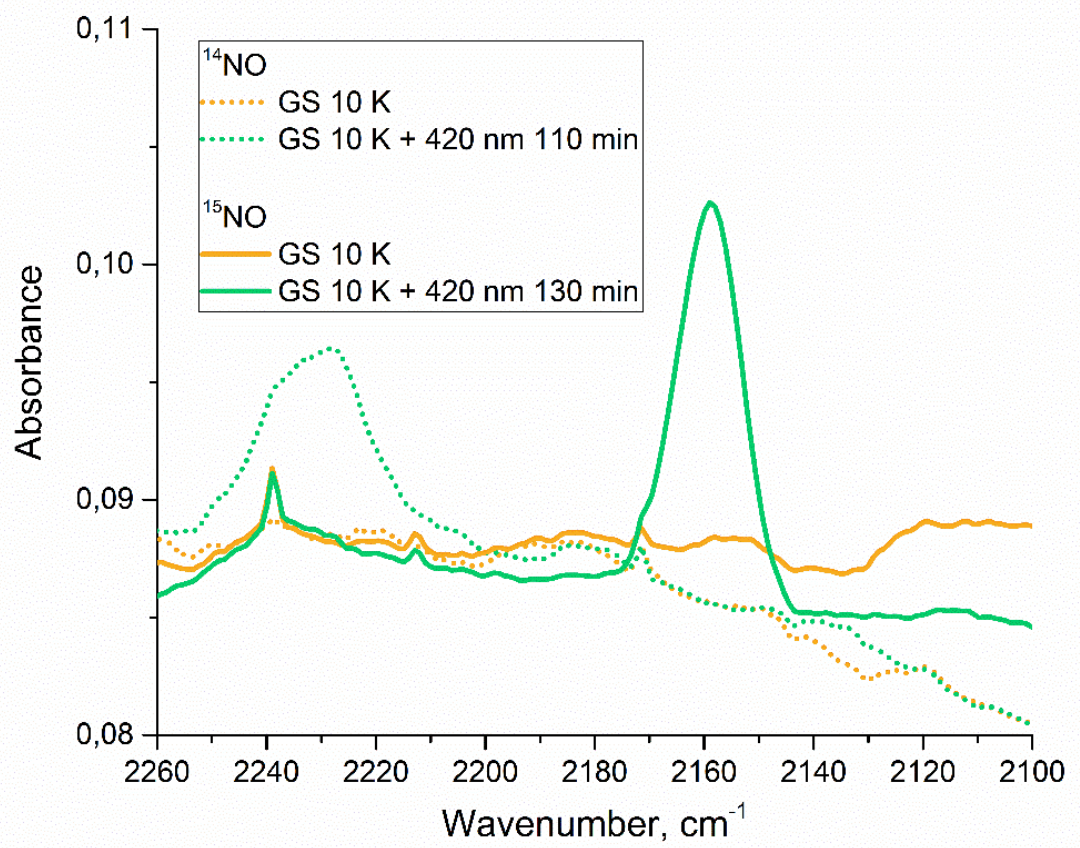

Fig. 10. The spectra after long-time irradiation of the of trans-[Ru( $\left.\left.\left.{ }^{14 / 15} \mathrm{NO}\right)(\mathrm{py})_{4} \mathrm{~F}\right](\mathrm{ClO})_{4}\right)_{2}$ by the $420 \mathrm{~nm}$ light.

The mechanism of $\mathrm{N}_{2} \mathrm{O}$ formation in solution when starting from a nitrosyl compound could comprise the formation of monometallic $\left\{\mathrm{M}-\left(\mathrm{K}^{2}-\mathrm{ONNO}\right)\right\}$ (bonding through two oxygen atoms) or bimetallic 
$\left\{\mathrm{M}_{2}-\mu-(\mathrm{NOON})\right\}$ (bonding through bridged nitrogen atoms) intermediates [62-65]. Also, the ability of hyponitrite compounds to release $\mathrm{N}_{2} \mathrm{O}$ in the solid state after light excitation has been reported [60]. In the current case, assuming the release of $\mathrm{N}_{2} \mathrm{O}$, this would rather indicate the formation of $\left\{\mathrm{Ru}-\left(\mathrm{k}^{2}-\mathrm{ONNO}\right)\right\}$ in a monomolecular site. Moreover, the formation of linkage isomers would be expected to favor the generation of a $\left\{\mathrm{Ru}-\left(\mathrm{K}^{2}-\mathrm{ONNO}\right)\right\}$ intermediate. In this context, we recall that the mechanism of the MS1 formation using blue light irradiation can be described as a consecutive reaction involving two excitation-relaxation steps and thus involving two photons GS $\rightarrow$ MS2 $\rightarrow$ MS1, where the MS2 is an intermediate state $[23,66]$. The mechanism was extensively studied theoretically, where it was shown that this reaction is rather a multistep excitation-relaxation process, which involves several nonadiabatic intersystem crossing processes between the singlet and triplet states of all three involved isomers GS, MS2, and MS1 [67-70]. Furthermore, it was reported that the mechanism of NO release in solutions might also involve the formation of the linkage isomers MS2 and MS1 $[6,15,16]$. However, given the static conditions of our experiments, it is impossible to unravel the mechanism, further investigations are required including usage of time-resolved techniques.

\section{Conclusions}

Detailed analysis of the experimental and calculated IR-spectra of GS (Ru-NO), MS1 (Ru-ON) and MS2 $\left(\mathrm{Ru}-\eta^{2}-(\mathrm{NO})\right)$ NO-linkage isomers of labelled trans-[Ru( $\left.\left.{ }^{14 / 15} \mathrm{NO}\right)(\mathrm{py})_{4} \mathrm{~F}\right]\left(\mathrm{ClO}_{4}\right)_{2}$ complexes has afforded to unambiguously assign the experimentally observed bands to vibrational modes of the complex. Whereas $v(\mathrm{NO})$ bands of GS and MS1 show one mode of $v(N O)$, the $v(N O)$ band in MS2 exhibits two modes: the pure $v(N O)$ stretching vibration, and a mixed $v(\mathrm{NO})$ stretch involving a stretching vibration of pyridine rings. $A$ more complex behavior of the $v(\mathrm{Ru}-(\mathrm{NO})), \delta(\mathrm{Ru}-(\mathrm{N}-\mathrm{O}))$ and $v(\mathrm{Ru}-\mathrm{F})$ and corresponding combined vibrations is observed in the lowenergy range of the spectra. For all three linkage isomers the $v(\mathrm{Ru}-(\mathrm{NO}))$ vibrational mode is associated with a small fraction of the $v(\mathrm{Ru}-\mathrm{F})$ vibration and vice versa. A similar situation is found for the $\delta(\mathrm{Ru}-(\mathrm{N}-\mathrm{O}))$ mode, which can comprise stretching or bending vibrations of pyridine rings. Hence, the low-energy bands are not pure, but can be considered as complex vibrations with the presence of dominant modes.

The change of the NO coordination type leads to a drastic change of the energy of $v(R u-(N O))$ and $v(R u-F)$ bands: from GS to MS1 and MS2 the $v(\mathrm{Ru}-(\mathrm{NO}))$ band shifts to lower energy while the $\mathrm{v}(\mathrm{Ru}-\mathrm{F})$ band shifts to higher energies. Moreover, there is an almost linear correlation between the Ru-(NO) and Ru- $F$ calculated bond lengths and the position of the corresponding vibrational bands (see Fig. S9): increase of the Ru-(NO) bond length leads to the decrease of the energy of $v(R u-(N O))$ band; decrease of the Ru- $F$ bond length leads to the increase of the energy of the $\mathrm{v}(\mathrm{Ru}-\mathrm{F})$ band. We suggest that this dependence can be used for a qualitative prediction of the Ru-(NO) and Ru-

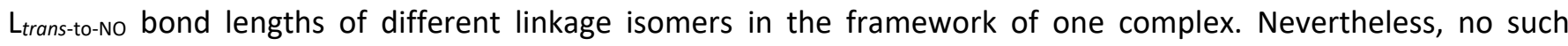
correlation is found for $\delta(\mathrm{Ru}-\mathrm{F})$ or $\delta(\mathrm{Ru}-(\mathrm{N}-\mathrm{O}))$ modes. Finally, the long-time irradiation of the complex induces release of $\mathrm{NO}$ followed by the formation of nitrous oxide $\mathrm{N}_{2} \mathrm{O}$. Supposedly, the mechanism of the $\mathrm{N}_{2} \mathrm{O}$ release comprises the formation of a $\left\{\mathrm{Ru}-\left(\mathrm{K}^{2}-\mathrm{ONNO}\right)\right\}$ intermediate, similar to known reactions $[60,62-65]$.

\section{Acknowledgements}

This investigation was supported by the Russian Basic Research Foundation (Project 19-03-00594). Artem Mikhailov is grateful for financial support from the Eiffel excellence bourse program (Grant P730329G). High Performance Computing resources were partially provided by the EXPLOR centre hosted by the University de Lorraine.

\section{References}

[1] P. Coppens, I. Novozhilova, A. Kovalevsky, Photoinduced Linkage Isomers of Transition-Metal 
Nitrosyl Compounds and Related Complexes, Chem. Rev. 102 (2002) 861-884.

https://doi.org/10.1021/cr000031c.

[2] M.J. Rose, P.K. Mascharak, Photoactive ruthenium nitrosyls: Effects of light and potential application as NO donors, Coord. Chem. Rev. 252 (2008) 2093-2114.

https://doi.org/10.1016/j.ccr.2007.11.011.

[3] D. Schaniel, M. Imlau, T. Weisemoeller, T. Woike, K.W. Krämer, H.-U. Güdel, Photoinduced Nitrosyl Linkage Isomers Uncover a Variety of Unconventional Photorefractive Media, Adv. Mater. 19 (2007) 723-726. https://doi.org/10.1002/adma.200601378.

[4] J. Cheng, K. He, Z. Shen, G. Zhang, Y. Yu, J. Hu, Nitric Oxide (NO)-Releasing Macromolecules: Rational Design and Biomedical Applications, Front. Chem. 7 (2019) 1-8. https://doi.org/10.3389/fchem.2019.00530.

[5] R.G. Teixeira, D.C. Belisario, X. Fontrodona, I. Romero, A.I. Tomaz, M.H. Garcia, C. Riganti, A. Valente, Unprecedented collateral sensitivity for cisplatin-resistant lung cancer cells presented by new ruthenium organometallic compounds, Inorg. Chem. Front. (2021). https://doi.org/10.1039/D0QI01344G.

[6] A.A. Mikhailov, D. V. Khantakova, V.A. Nichiporenko, E.M. Glebov, V.P. Grivin, V.F. Plyusnin, V. V. Yanshole, D. V. Petrova, G.A. Kostin, I.R. Grin, Photoinduced inhibition of DNA repair enzymes and the possible mechanism of photochemical transformations of the ruthenium nitrosyl complex [RuNO(ß-Pic) 2 (NO 2 ) 2 OH], Metallomics. 11 (2019) 1999-2009. https://doi.org/10.1039/C9MT00153K.

[7] A.B. Seabra, G.Z. Justo, P.S. Haddad, State of the art, challenges and perspectives in the design of nitric oxide-releasing polymeric nanomaterials for biomedical applications, Biotechnol. Adv. 33 (2015) 1370-1379. https://doi.org/10.1016/j.biotechadv.2015.01.005.

[8] E. O'Toole, M. V. Doucet, E. Sherwin, A. Harkin, Novel Targets in the Glutamate and Nitric Oxide Neurotransmitter Systems for the Treatment of Depression, in: Syst. Neurosci. Depress., Elsevier, 2016: pp. 81-113. https://doi.org/10.1016/B978-0-12-802456-0.00003-0.

[9] S. Hasan, N. Thomas, B. Thierry, C.A. Prestidge, Biodegradable nitric oxide precursor-loaded micro- and nanoparticles for the treatment of Staphylococcus aureus biofilms, J. Mater. Chem. B. 5 (2017) 1005-1014. https://doi.org/10.1039/C6TB03290G.

[10] A.B. Seabra, N. Durán, Nitric Oxide Donors for Treating Neglected Diseases, in: Nitric Oxide Donors, Elsevier, 2017: pp. 25-53. https://doi.org/10.1016/B978-0-12-809275-0.00002-8.

[11] N.C. Adusumilli, D. Zhang, J.M. Friedman, A.J. Friedman, Harnessing nitric oxide for preventing, limiting and treating the severe pulmonary consequences of COVID-19, Nitric Oxide. 103 (2020) 4-8. https://doi.org/10.1016/j.niox.2020.07.003.

[12] S. Åkerström, M. Mousavi-Jazi, J. Klingström, M. Leijon, A. Lundkvist, A. Mirazimi, Nitric Oxide Inhibits the Replication Cycle of Severe Acute Respiratory Syndrome Coronavirus, J. Virol. 79 (2005) 1966-1969. https://doi.org/10.1128/JVI.79.3.1966-1969.2005.

[13] S. Åkerström, V. Gunalan, C.T. Keng, Y.-J. Tan, A. Mirazimi, Dual effect of nitric oxide on SARS-CoV replication: Viral RNA production and palmitoylation of the S protein are affected, Virology. 395 (2009) 1-9. https://doi.org/10.1016/j.virol.2009.09.007.

[14] J.C. Pieretti, O. Rubilar, R.B. Weller, G.R. Tortella, A.B. Seabra, Nitric oxide (NO) and nanoparticles - Potential small tools for the war against COVID-19 and other human coronavirus infections, Virus Res. 291 (2021) 198202. https://doi.org/10.1016/j.virusres.2020.198202.

[15] J.S. García, F. Alary, M. Boggio-Pasqua, I.M. Dixon, J.-L. Heully, Is photoisomerization required for NO photorelease in ruthenium nitrosyl complexes?, J. Mol. Model. 22 (2016) 284. 
https://doi.org/10.1007/s00894-016-3138-2.

[16] I. Szundi, M.J. Rose, I. Sen, A.A. Eroy-Reveles, P.K. Mascharak, Ó. Einarsdóttir, A New Approach for Studying Fast Biological Reactions Involving Nitric Oxide: Generation of NO Using Photolabile Ruthenium and Manganese NO Donors, Photochem. Photobiol. 82 (2006) 1377.

https://doi.org/10.1562/2006-07-25-RC-984.

[17] Z. Tahri, R. Lepski, K.-Y. Hsieh, E.-E. Bendeif, S. Pillet, P. Durand, T. Woike, D. Schaniel, Properties of metastable linkage $\mathrm{NO}$ isomers in $\mathrm{Na} 2[\mathrm{Fe}(\mathrm{CN}) 5 \mathrm{NO}] \cdot 2 \mathrm{H} 2 \mathrm{O}$ incorporated in mesopores of silica xerogels, Phys. Chem. Chem. Phys. 14 (2012) 3775. https://doi.org/10.1039/c2cp23607a.

[18] B. Cormary, I. Malfant, L. Valade, New photochromic xerogels composites based on nitrosyl complexes, J. Sol-Gel Sci. Technol. 52 (2009) 19-23. https://doi.org/10.1007/s10971-009-2034-y.

[19] D. Schaniel, M. Nicoul, T. Woike, Ultrafast reversible ligand isomerisation in $\mathrm{Na} 2[\mathrm{Fe}(\mathrm{CN}) 5 \mathrm{NO}] \cdot 2 \mathrm{H}$ 20 single crystals, Phys. Chem. Chem. Phys. 12 (2010) 9029-9033.

https://doi.org/10.1039/b924528f.

[20] Y. Morioka, A. Ishikawa, H. Tomizawa, E. Miki, Light-induced metastable states in nitrosylruthenium complexes containing ethylenediamine and oxalate ion ligands, J. Chem. Soc. Dalt. Trans. 54 (2000) 781-786. https://doi.org/10.1039/a906429j.

[21] A. Mikhailov, T.S. Sukhikh, N. Kuratieva, D.P. Pishchur, G. Kostin, Remarkable thermal stability of light-induced Ru-ON linkage isomers in mixed salts of ammine ruthenium complex with trans-ONRu-F coordinate, Dalt. Trans. (2021). https://doi.org/10.1039/d0dt04323k.

[22] G.A. Kostin, A.A. Mikhailov, N. V. Kuratieva, D.P. Pishchur, A.N. Makhinya, High thermal stability of the Ru-ON (MS1) linkage isomer of the ruthenium nitrosyl complex [RuNO(Py)4F](ClO4)2 with the trans NO-Ru-F coordinate, New J. Chem. 42 (2018) 18928-18934.

https://doi.org/10.1039/c8nj04620d.

[23] A.A. Mikhailov, E. Wenger, G.A. Kostin, D. Schaniel, Room-Temperature Photogeneration of Nitrosyl Linkage Isomers in Ruthenium Nitrosyl Complexes, Chem. - A Eur. J. 25 (2019) 75697574. https://doi.org/10.1002/chem.201901205.

[24] A.A. Mikhailov, V.Y. Komarov, A.S. Sukhikh, D.P. Pishchur, D. Schaniel, G.A. Kostin, The impact of counterion on the metastable state properties of nitrosyl ruthenium complexes, New J. Chem. 44 (2020) 18014-18024. https://doi.org/10.1039/DONJ04436A.

[25] A. Mikhailov, V. Vuković, C. Kijatkin, E. Wenger, M. Imlau, T. Woike, G. Kostin, D. Schaniel, Combining photoinduced linkage isomerism and nonlinear optical properties in ruthenium nitro-syl complexes, Acta Crystallogr. Sect. B Struct. Sci. Cryst. Eng. Mater. 75 (2019) 1152-1163. https://doi.org/10.1107/S205252061901357X.

[26] D. Schaniel, B. Cormary, I. Malfant, L. Valade, T. Woike, B. Delley, K.W. Krämer, H.U. Güdel, Photogeneration of two metastable NO linkage isomers with high populations of up to $76 \%$ in trans-[RuCl(py)4(NO)][PF6] 2-1/2;H2O, Phys. Chem. Chem. Phys. 9 (2007) 3717-3724. https://doi.org/10.1039/b704778a.

[27] N. Casaretto, S. Pillet, E.E. Bendeif, D. Schaniel, A.K.E. Gallien, P. Klüfers, T. Woike, Multiple lightinduced NO linkage isomers in the dinitrosyl complex [RuCl(NO) 2 (PPh 3 ) 2 ]BF 4 unravelled by photocrystallographic and IR analysis, IUCrJ. 2 (2015) 35-44.

https://doi.org/10.1107/S2052252514023598.

[28] N. Casaretto, B. Fournier, S. Pillet, E.E. Bendeif, D. Schaniel, A.K.E. Gallien, P. Klüfers, T. Woike, Photo-induced linkage NO isomers in the dinitrosyl complex [Ru(NO) 2 (PCy 3 ) 2 Cl](BF 4 ) identified by photocrystallography and IR-spectroscopy, CrystEngComm. 18 (2016) 7260-7268. https://doi.org/10.1039/C6CE00735J. 
[29] D. Schaniel, E.-E. Bendeif, T. Woike, H.-C. Böttcher, S. Pillet, Wavelength-selective photoisomerisation of nitric oxide and nitrite in a rhodium complex, CrystEngComm. 20 (2018) 7100-7108. https://doi.org/10.1039/C8CE01345D.

[30] G.A. Kostin, A.O. Borodin, A.A. Mikhailov, N. V. Kuratieva, B.A. Kolesov, D.P. Pishchur, T. Woike, D. Schaniel, Photocrystallographic, Spectroscopic, and Calorimetric Analysis of Light-Induced Linkage NO Isomers in [RuNO(NO 2$)_{2}$-(pyridine) ${ }_{2}$ OH], Eur. J. Inorg. Chem. 2015 (2015) 49054913. https://doi.org/10.1002/ejic.201500702.

[31] B. Cormary, I. Malfant, M. Buron-Le Cointe, L. Toupet, B. Delley, D. Schaniel, N. Mockus, T. Woike, K. Fejfarová, V. Petříček, M. Dušek, [Ru(py) 4 Cl(NO)](PF 6 ) $2 \cdot 0.5 \mathrm{H} 2$ O: a model system for structural determination and ab initio calculations of photo-induced linkage NO isomers, Acta Crystallogr. Sect. B Struct. Sci. 65 (2009) 612-623. https://doi.org/10.1107/S0108768109027207.

[32] V.I. Baranovskii, D.A. Mal'tsev, O. V. Sizova, Excited-state potential surfaces of ruthenium nitrosyl complexes: conical intersections and the Jahn-Teller effect, Russ. Chem. Bull. 61 (2012) 973-979. https://doi.org/10.1007/s11172-012-0140-4.

[33] E. Coronado, S. Klokishner, O. Reu, B. Tsukerblat, A pseudo-Jahn-Teller model of the photochromic effect in sodium nitroprusside, Polyhedron. 22 (2003) 2527-2535. https://doi.org/10.1016/S0277-5387(03)00172-4.

[34] M. Atanasov, T. Schönherr, The unique spectroscopic behavior of the Fe(III)-nitroprusside: a DFT study of the vibronic coupling in the ground and in the lowest excited state, J. Mol. Struct. THEOCHEM. 592 (2002) 79-93. https://doi.org/10.1016/S0166-1280(02)00229-4.

[35] M.J. Cleare, W.P. Griffith, Infrared spectra of isotopically substituted nitro-, nitrito-, and nitrosyl complexes, J. Chem. Soc. A Inorganic, Phys. Theor. (1967) 1144. https://doi.org/10.1039/j19670001144.

[36] M.J. Cleare, W.P. Griffith, Halogeno-carbonyl and -nitrosyl complexes of the platinum metals, and their vibrational spectra, J. Chem. Soc. A Inorganic, Phys. Theor. (1969) 372. https://doi.org/10.1039/j19690000372.

[37] T. Togano, H. Kuroda, N. Nagao, Y. Maekawa, H. Nishimura, F.S. Howell, M. Mukaida, Synthesis, properties and molecular structure of trans-hydroxobis(2, 2'-bipyridine)nitrosylruthenium(2+): influence of axial ligand on characteristics of nitrosyl moiety in trans-[Ru(NO)XL4]n+ $(\mathrm{X}=\mathrm{OH}, \mathrm{Cl}$; L=py, 1/2(bpy)) type complexes, Inorganica Chim. Acta. 196 (1992) 57-63. https://doi.org/10.1016/S0020-1693(00)82960-6.

[38] K. Dallmann, W. Preetz, Darstellung, Kristallstruktur, Schwingungsspektren und Normalkoordinatenanalyse von [Os(acac)3]/ Synthesis, Crystal Structure, Vibrational Spectra, and Normal Coordinate Analysis of [Os(acac)3], Zeitschrift Für Naturforsch. B. 53 (1998) 232-238. https://doi.org/10.1515/znb-1998-0216.

[39] M. Weidemann, S. Sievertsen, H. Homborg, Synthese und Eigenschaften von (Acido)(nitrosyl)phthalocyaninato(2-)ruthenium, Zeitschrift Für Anorg. Und Allg. Chemie. 624 (1998) 909-918. https://doi.org/10.1002/(SICI)1521-3749(199805)624:5<909::AIDZAAC909>3.0.CO;2-F.

[40] A.C. Merkle, A.B. McQuarters, N. Lehnert, Synthesis, spectroscopic analysis and photolabilization of water-soluble ruthenium(iii)-nitrosyl complexes, Dalt. Trans. 41 (2012) 8047. https://doi.org/10.1039/c2dt30464c.

[41] F. Paulat, T. Kuschel, C. Näther, V.K.K. Praneeth, O. Sander, N. Lehnert, Spectroscopic Properties and Electronic Structure of Pentammineruthenium(II) Dinitrogen Oxide and Corresponding Nitrosyl Complexes: Binding Mode of N 20 and Reactivity, Inorg. Chem. 43 (2004) 6979-6994. https://doi.org/10.1021/ic049302i. 
[42] T. Woike, S. Haussühl, Infrared-spectroscopic and differential scanning calorimetric studies of the two light-induced metastable states in K2[Ru(NO2)4(OH)(NO)], Solid State Commun. 86 (1993) 333-337. https://doi.org/10.1016/0038-1098(93)90384-Y.

[43] J.A. Güida, O.E. Piro, P.S. Schaiquevich, P.J. Aymonino, Infrared absorption spectra of electronically excited long-lived metastable states in $\mathrm{Na} 2[\mathrm{Ru}(\mathrm{CN}) 5 \mathrm{NO}] \cdot 2 \mathrm{H} 2 \mathrm{O}$, Solid State Commun. 101 (1997) 471-475. https://doi.org/10.1016/S0038-1098(96)00616-3.

[44] K. Ookubo, Y. Morioka, H. Tomizawa, E. Miki, Vibrational spectroscopic study of light-induced metastable states of ethylenediaminenitrosylruthenium(II) complexes, J. Mol. Struct. 379 (1996) 241-247. https://doi.org/10.1016/0022-2860(95)09197-1.

[45] D. Schaniel, T. Woike, L. Kushch, E. Yagubskii, Photoinduced nitrosyl linkage isomers in complexes based on the photochromic cation [RuNO(NH3)5]3+ with the paramagnetic anion $[\mathrm{Cr}(\mathrm{CN}) 6] 3-$ and the diamagnetic anions [Co(CN)6]3- and [ZrF6]2-, Chem. Phys. 340 (2007) 211-216. https://doi.org/10.1016/j.chemphys.2007.08.023.

[46] B. Cormary, S. Ladeira, K. Jacob, P.G. Lacroix, T. Woike, D. Schaniel, I. Malfant, Structural Influence on the Photochromic Response of a Series of Ruthenium Mononitrosyl Complexes, Inorg. Chem. 51 (2012) 7492-7501. https://doi.org/10.1021/ic202702r.

[47] G.A. Kostin, A.A. Mikhailov, N. V. Kuratieva, S. V. Tkachev, D. Schaniel, T. Woike, Reaction of $\left[\mathrm{RuNO}\left(\mathrm{NO}_{2}\right)_{4} \mathrm{OH}\right]^{2-}$ with Sulfamic Acid as a Pathway to Mixed Nitro Pyridine Ruthenium Nitrosyl Complexes, Eur. J. Inorg. Chem. 2016 (2016) 4045-4053.

https://doi.org/10.1002/ejic.201600477.

[48] I.S. Fomenko, A.A. Mikhailov, V. Vorobyev, N. V. Kuratieva, G.A. Kostin, D. Schaniel, V.A. Nadolinny, A.L. Gushchin, Solution and solid-state light-induced transformations in heterometallic vanadium-ruthenium nitrosyl complex, J. Photochem. Photobiol. A Chem. 407 (2021) 113044. https://doi.org/10.1016/j.jphotochem.2020.113044.

[49] E. Orlowska, M. V Babak, O. Dömötör, E.A. Enyedy, P. Rapta, M. Zalibera, L. Bučinský, M. Malček, C. Govind, V. Karunakaran, H. Ang, V.B. Arion, NO Releasing and Anticancer Properties of Octahedral Ruthenium-Nitrosyl Complexes with Equatorial $1 \mathrm{H}$-indazole Ligands, (n.d.).

[50] A.N. Makhinya, M.A. Il'in, R.D. Yamaletdinov, I.A. Baidina, S. V. Tkachev, A.P. Zubareva, I. V. Korol'kov, D.A. Piryazev, Synthesis, some properties, and crystalline modifications of fac[Ru(NO)(Py)2Cl3], Russ. J. Coord. Chem. 42 (2016) 768-774. https://doi.org/10.1134/S1070328416120046.

[51] V.A. Emel'yanov, M.A. Fedotov, A. V. Belyaev, S. V. Tkachev, A multinuclear magnetic resonance study of transformations of ruthenium(II) nitrosyl chloride complexes in aqueous solutions, Russ. J. Inorg. Chem. 58 (2013) 956-963. https://doi.org/10.1134/s003602361308007x.

[52] G. te Velde, F.M. Bickelhaupt, E.J. Baerends, C. Fonseca Guerra, S.J.A. van Gisbergen, J.G. Snijders, T. Ziegler, Chemistry with ADF, J. Comput. Chem. 22 (2001) 931-967. https://doi.org/10.1002/jcc.1056.

[53] K. Kim, K.D. Jordan, Comparison of Density Functional and MP2 Calculations on the Water Monomer and Dimer, J. Phys. Chem. 98 (1994) 10089-10094. https://doi.org/10.1021/j100091a024.

[54] E. van Lenthe, E.J. Baerends, J.G. Snijders, Relativistic regular two-component Hamiltonians, J. Chem. Phys. 99 (1993) 4597-4610. https://doi.org/10.1063/1.466059.

[55] S.J. Clark, M.D. Segall, C.J. Pickard, P.J. Hasnip, M.I.J. Probert, K. Refson, M.C. Payne, First principles methods using CASTEP, Zeitschrift Für Krist. - Cryst. Mater. 220 (2005) 567-570. https://doi.org/10.1524/zkri.220.5.567.65075. 
[56] J.P. Perdew, K. Burke, M. Ernzerhof, Generalized Gradient Approximation Made Simple, Phys. Rev. Lett. 77 (1996) 3865-3868. https://doi.org/10.1103/PhysRevLett.77.3865.

[57] D.R. Hamann, M. Schlüter, C. Chiang, Norm-Conserving Pseudopotentials, Phys. Rev. Lett. 43 (1979) 1494-1497. https://doi.org/10.1103/PhysRevLett.43.1494.

[58] R.L. Hudson, M.J. Loeffler, P.A. Gerakines, Infrared spectra and band strengths of amorphous and crystalline N2O, J. Chem. Phys. 146 (2017) 024304. https://doi.org/10.1063/1.4973548.

[59] A. Łapiński, J. Spanget-Larsen, J. Waluk, J.G. Radziszewski, Vibrations of nitrous oxide: Matrix isolation Fourier transform infrared spectroscopy of twelve N2O isotopomers, J. Chem. Phys. 115 (2001) 1757-1764. https://doi.org/10.1063/1.1383031.

[60] M.E. Chacón Villalba, C.A. Franca, J.A. Güida, Photo release of nitrous oxide from the hyponitrite ion studied by infrared spectroscopy. Evidence for the generation of a cobalt-N2O complex. Experimental and DFT calculations, Spectrochim. Acta Part A Mol. Biomol. Spectrosc. 176 (2017) 189-196. https://doi.org/10.1016/j.saa.2017.01.003.

[61] D. Schaniel, T. Woike, B. Delley, C. Boskovic, H.-U. Güdel, Photogeneration of metastable side-on $\mathrm{N} 2$ linkage isomers in [Ru(NH3)5N2]Cl2, [Ru(NH3)5N2] Br2 and [Os(NH3)5N2]Cl2, Phys. Chem. Chem. Phys. 10 (2008) 5531. https://doi.org/10.1039/b806933f.

[62] C. Gaviglio, J. Pellegrino, D. Milstein, F. Doctorovich, NO disproportionation by a $\{$ RhNO\}9 pincertype complex, Dalt. Trans. 46 (2017) 16878-16884. https://doi.org/10.1039/c7dt03944a.

[63] C. Van Stappen, N. Lehnert, Mechanism of N-N Bond Formation by Transition Metal-Nitrosyl Complexes: Modeling Flavodiiron Nitric Oxide Reductases, Inorg. Chem. 57 (2018) 4252-4269. https://doi.org/10.1021/acs.inorgchem.7b02333.

[64] S. Kundu, P.N. Phu, P. Ghosh, S.A. Kozimor, J.A. Bertke, S.C.E. Stieber, T.H. Warren, Nitrosyl Linkage Isomers: NO Coupling to N $2 \mathrm{O}$ at a Mononuclear Site, J. Am. Chem. Soc. 141 (2019) 1415-1419. https://doi.org/10.1021/jacs.8b09769.

[65] Y. Arikawa, T. Asayama, Y. Moriguchi, S. Agari, M. Onishi, Reversible N-N Coupling of NO Ligands on Dinuclear Ruthenium Complexes and Subsequent N 2 O Evolution: Relevance to Nitric Oxide Reductase, J. Am. Chem. Soc. 129 (2007) 14160-14161. https://doi.org/10.1021/ja0763504.

[66] L. Khadeeva, W. Kaszub, M. Lorenc, I. Malfant, M. Buron-Le Cointe, Two-Step Photon Absorption Driving the Chemical Reaction in the Model Ruthenium Nitrosyl System [Ru(py)4CI(NO)](PF6)2·(1)/2H2O, 2016. https://doi.org/10.1021/acs.inorgchem.5b02572.

[67] F. Talotta, J.-L. Heully, F. Alary, I.M. Dixon, L. González, M. Boggio-Pasqua, Linkage Photoisomerization Mechanism in a Photochromic Ruthenium Nitrosyl Complex: New Insights from an MS-CASPT2 Study, J. Chem. Theory Comput. 13 (2017) 6120-6130. https://doi.org/10.1021/acs.jctc.7b00982.

[68] F. Talotta, M. Boggio-Pasqua, L. González, Early Relaxation Dynamics in the Photoswitchable Complex trans -[RuCl(NO)(py) 4 ] 2+, Chem. - A Eur. J. 26 (2020) 11522-11528. https://doi.org/10.1002/chem.202000507.

[69] F. Talotta, L. González, M. Boggio-Pasqua, CASPT2 Potential Energy Curves for NO Dissociation in a Ruthenium Nitrosyl Complex, Molecules. 25 (2020) 2613. https://doi.org/10.3390/molecules25112613.

[70] J. Sanz García, F. Alary, M. Boggio-Pasqua, I.M. Dixon, I. Malfant, J.-L. Heully, Establishing the Two-Photon Linkage Isomerization Mechanism in the Nitrosyl Complex trans -[RuCl(NO)(py) 4 ] 2+ by DFT and TDDFT, Inorg. Chem. 54 (2015) 8310-8318. https://doi.org/10.1021/acs.inorgchem.5b00998. 
